Check for updates

Cite this: Mater. Adv., 2020, 1,2182

Received 14th June 2020,

Accepted 13th August 2020

DOI: $10.1039 / \mathrm{d} 0 \mathrm{ma} 00415 \mathrm{~d}$

rsc.li/materials-advances

\section{Designing and controlling the morphology of spherical molecularly imprinted polymers}

\begin{abstract}
Hongzhi Lu, ${ }^{a}$ Hao Tian, ${ }^{\text {bc }}$ Changzheng Wang (D ${ }^{b}$ and Shoufang Xu (D)*c
Molecularly imprinted polymers (MIPs) display specific recognition ability for their template in shape, size and functional monomers. The morphology has an important influence on the binding capacity of MIPs, thus affecting the enrichment efficiency and detection sensitivity. In this critical review, we highlight the morphology design and control of spherical MIPs, mainly focusing on solid sphere, core-shell, hollow and mesoporous MIPs. The methods for preparation of MIPs of different morphologies are summarized, and typical TEM or SEM images are displayed. The influence of morphology on the application of MIPs is highlighted. Finally, we discuss the remaining challenges, and some significant attempts in further improving the morphology of MIPs are also proposed.
\end{abstract}

\section{Introduction}

Molecularly imprinted polymers (MIPs) are a class of polymers displaying specific recognition to template molecules. MIPs possess some prominent advantages, like structure predictability, chemical stability, recognition specificity and application universality. ${ }^{1,2}$ MIPs are prepared by pre-polymerization, polymerization and template removal in three consecutive steps, as shown

${ }^{a}$ School of Chemistry and Chemical Engineering, Linyi University, Linyi 276005, China

${ }^{b}$ Beijing Key Laboratory of Functional Materilas for Building Structure and Environment Remediation, Being University of Civil Engineering and Architecture, Beijing, 100044, China

${ }^{c}$ Laboratory of Functional Polymers, School of Materials Science and Engineering, Linyi University, Linyi 276005, China. E-mail: shfxu1981@163.com in Fig. $1 .^{3}$ When MIPs are placed in a complex sample matrix, the molecules matching the recognition sites can be specifically adsorbed. Due to the high selectivity, MIPs were widely used for sample pretreatment or chemical sensors. According to the polymerization mechanism, MIPs can be divided into organic MIPs and inorganic MIPs. Organic MIPs are prepared by polymerization of vinyl functional monomers such as methacrylic acid (MAA), acrylamide (AAm), 4-vinylpyridine (4-VP) with cross-linkers like ethylene glycol dimethacrylate (EGDMA), trimethylolpropane trimethacrylate (TRIM), or divinylbenzene (DVB) initiated by thermally sensitive or UV light sensitive initiators. Due to its tolerance to reagent purity, flexibility in terms of experimental setups and the wide range of commercially available functional monomers, the free-radical polymerization technique is widely used to prepare organic MIPs. Inorganic MIPs

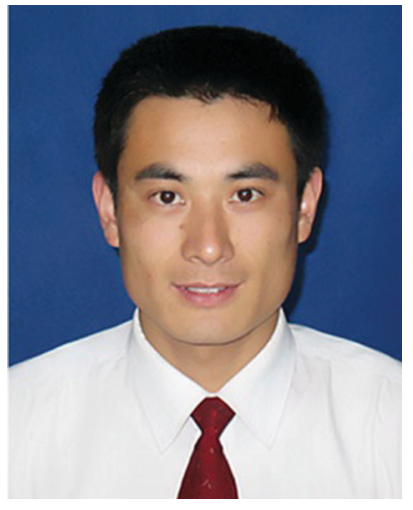

Hongzhi Lu received his Master's degree from Shandong Normal University in 2007. He is currently a lecturer at the School of Chemistry \& Chemical Engineering, Linyi University. His research interests focus on the synthesis and application of functional polymers.
Hongzhi Lu

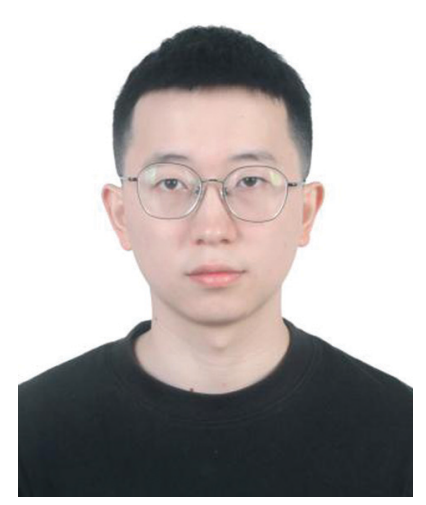

Hao Tian
Hao Tian received his $B E$ degree in water supply and drainage from Beijing University of Civil Engineering and Architecture in 2019. He is currently pursuing a Master's degree at the School of Environment and Engineering, Beijing University of Civil Engineering and Architecture under the supervision of Prof. Changzheng Wang and Prof. Shoufang $\mathrm{Xu}$. His research is focused on the preparation of molecularly imprinted polymers (MIPs). 

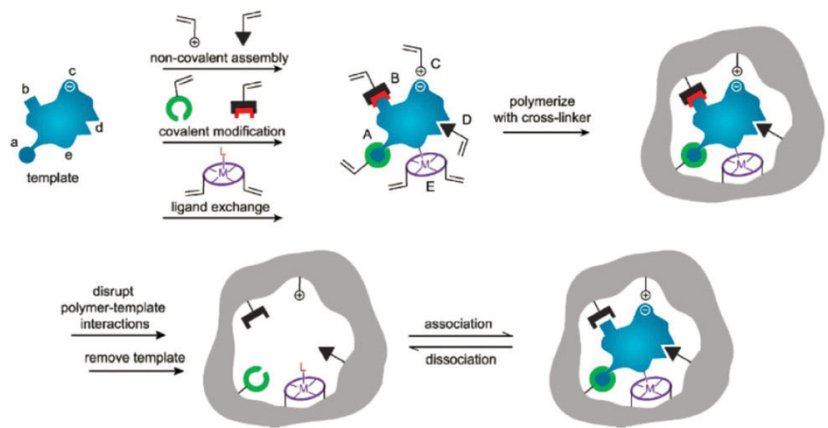

Fig. 1 Preparation process of MIPs including pre-polymerization, polymerization, and elution template as three steps. During the prepolymerization, functional monomers can bond with template by (i) noncovalent, (ii) electrostatic/ionic, (iii) covalent, (iv) semicovalent, and (v) metal centre coordination. Adapted from ref. 3. Copyright 2006 John Wiley and Sons.

are mainly prepared by condensation of tetraethoxysilane (TEOS) with functional monomers like 3-aminopropyltriethoxysilane (APTES) and 3-isocyanatopropylethoxysilane (IPTS) in alkaline conditions to get sol-gel silica. Inorganic MIPs display higher thermal and chemical stability, and recognition sites can be well maintained because silica exhibits minimal swelling in the presence of solvents. Recently, self-polymerization of dopamine in a weak alkaline aqueous solution has been developed to form MIPs for protein imprinting due to the hydrophilicity and biocompatibility of polydopamine (PDA). The polymerization mechanism of dopamine to form PDA was discussed in a review article. ${ }^{4}$ Based on the above polymerization methods, MIPs with different morphologies for different applications have been prepared.

In the past three years, a series of excellent reviews focused on the preparation ${ }^{5-7}$ and application of MIPs $^{8-18}$ have been published. In those review articles, ${ }^{2,6,7}$ the brief history of the molecular imprinting technique, the type of molecular imprinting (including noncovalent imprinting, covalent imprinting, semicovalent imprinting), and the essential elements of molecular imprinting like functional monomer, cross-linker, target template,
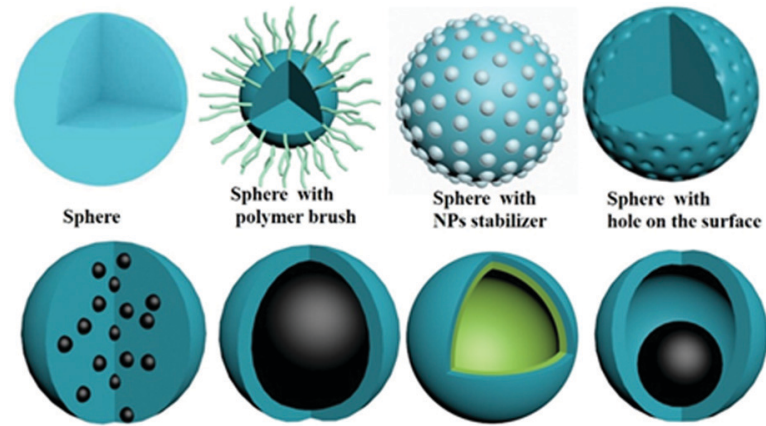

hole on the surface
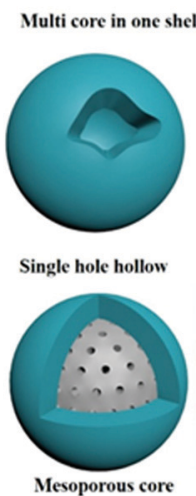

Solid shell

Core shell

Hollow

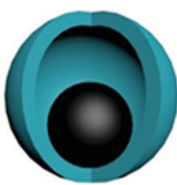

York shell
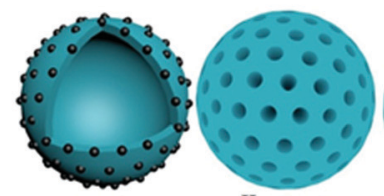

Homogeneous Homogeneous
mesoporous
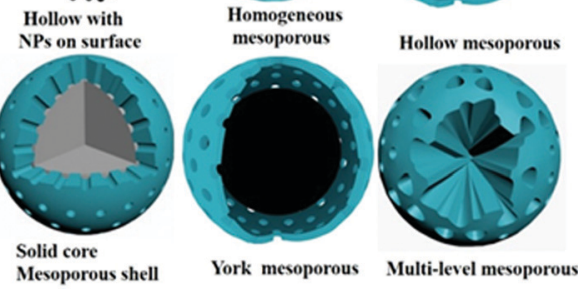

Fig. 2 Typical morphologies of spherical MIPs

initiators and porogens have been introduced in detail many times. However, to the best of our knowledge, there are few review articles on the morphology control of MIPs. ${ }^{19-21}$ The morphology has an important influence on the binding capacity of MIPs, thus affecting the enrichment efficiency and detection sensitivity. Therefore, design and control of morphology are important in the field of molecular imprinting. The morphology of MIPs has evolved from irregular particles to regular spheres, hierarchical structures, and films. As shown in Fig. 2, MIP spheres are changeable and controllable, and widely used in the fields of filling columns, adsorption separation and sensor construction. So in this review, instead of providing a comprehensive review of MIPs, we focus on

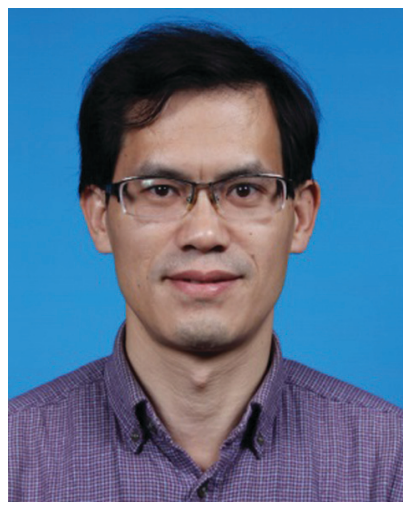

Changzheng Wang
Dr Changzheng Wang received his MS degree (2005) from Yunnan Normal University (YNU) and $P h D$ degree (2008) from Beijing Normal University (BNU). Currently, he is a professor in the School of Environment and Engineering of Beijing University of Civil Engineering and Architecture (BUCEA). His research focuses on the synthesis of functional nanomaterials for environmental remediation and their applications in photocatalysis and electrocatalysis.

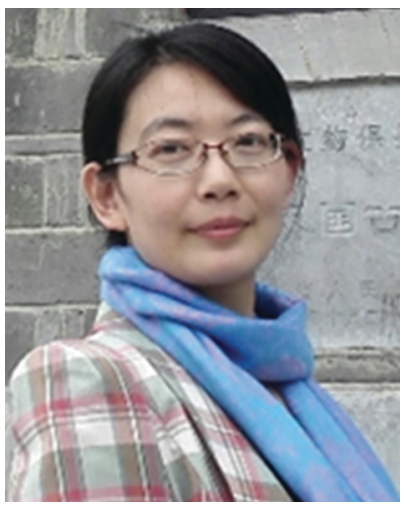

Shoufang Xu
Shoufang $X u$ received her $P h D$ degree from the Yantai Institute of Coastal Zone Research, Chinese Academy of Sciences in 2012. She is currently a professor at the School of Materials Science and Engineering, Linyi University. She is the academic leader of Youth Innovation team of Shandong province. Her research interests focus on the preparation of molecularly imprinted polymers (MIPS) and the application of MIPs in the separation and analysis of typical organic pollutants. 
the preparation of MIPs with controlled spherical morphologies taking a small fraction of the literature, and the effect of morphology on MIP performance is discussed. We hope that this review article will be of guiding significance to researchers engaged in the design of MIPs and bridge the gap between the preparation method and application of MIPs. It should be noted that one type of MIP particles may have multiple characteristic morphologies at the same time, such as core-shell mesoporous MIPs can be classified as core-shell MIPs or mesoporous MIPs. We discuss them under the most representative mesoporous morphologies.

\section{Spherical MIPs}

Initially, MIPs were simply prepared by bulk polymerization. Monomers, template molecules, cross-linker and a small amount of solvents were polymerized to obtain bulk polymers. ${ }^{22-24}$ The polymers needed to be ground and sieved to get irregular polymer particles before being used to pack a chromatography column or SPE column. Bulk polymers displayed obvious advantages like simple preparation and high polymer yield. At the same time, there were several obvious shortcomings, like time-consuming post-treatment procedure, low-affinity binding sites, poor site accessibility and low binding capacity stemming from big and irregular particle size. It was necessary to prepare monodisperse spherical MIPs. Inorganic spherical MIPs can be obtained by hydrolysis of TEOS in alkaline condition by the classical Stöber method. The preparation process is simple and repeatable, which is not discussed here. Organic spherical MIPs are discussed in this section.

\subsection{Spherical MIPs by precipitation polymerization}

Spherical MIPs prepared by precipitation polymerization exhibit highly uniform particle size and clean surface because dispersants and surfactants are not needed to stabilize polymer droplets. During precipitation polymerization, monomers, templates and cross-linkers are dispersed in a large amount of solvent (generally, solvent accounts for $95 \%$ of the polymerization system). The resulting polymer is insoluble in the solvent and precipitates from the solvent to form regular spherical MIPs. For example, as early as 2003 , Row ${ }^{25}$ prepared caffeineimprinted uniform spherical MIPs by precipitation polymerization using acetonitrile as the dilute solvent with a concentration of 96\%, MAA as the monomer and EGDMA as the crosslinker. The average particle size of MIPs was about $400 \mathrm{~nm}$ while the average particle size of spherical NIPs was $800 \mathrm{~nm}$, which indicated that the template could affect the particle size. Subsequently, precipitation polymerization was employed to prepare many spherical MIPs for selective recognition of tetracycline, ${ }^{26}$ vitamin $\mathrm{E},{ }^{27}$ etc. The key point of this method was the solubility and amount of solvent. Low amount of solvent would result in the adhesion and agglomeration of polymer particles, and it was hard to get monodispersed spherical MIPs. For some hydrophilic templates, modified precipitation polymerization can be adopted. ${ }^{28,29}$ In this method, the hydrophilic template is first dissolved in a small portion of water, and then
MIPs are prepared by precipitation polymerization using acetonitrile or toluene as solvent.

Spherical MIPs prepared by precipitation polymerization often display a broad size distribution due to uncontrollable chain transfer and termination reactions of free radical polymerization. To get monodisperse MIPs, living/controlled radical polymerization techniques ${ }^{30-35}$ were adopted, in which reversible addition-fragmentation chain transfer (RAFT) polymerization was the most employed. RAFT precipitation polymerization (RAFTPP) can be carried out by introducing a suitable chain transfer agent (RAFT agent, normally a thiocarbonylthio or dithiobenzoate compound) into a conventional precipitation polymerization system. In our previous work, ${ }^{30}$ we prepared atrazine-imprinted polymers by RAFTPP and the resultant RAFT-MIPs displayed uniform spherical shape with a rough surface, leading to an improvement in imprinting efficiency. With this advantage, RAFTPP was employed to prepare spherical MIPs for nicotine ${ }^{31}$ glutathione, ${ }^{32}$ etc. Atom transfer radical precipitation polymerization (ATRPP) also was employed for preparation spherical MIPs. ${ }^{33}$ The monodispersity was improved by living polymerization.

The process of traditional precipitation polymerization often needed $24 \mathrm{~h}$ at approximately $60{ }^{\circ} \mathrm{C}$. To shorten the polymerization time, distillation precipitation polymerization (DPP) was developed, in which some of the solvent was distilled off during the polymerization process to accelerate the precipitation of MIPs. ${ }^{36-38} \mathrm{Li}^{37}$ prepared MIPs by DPP for detection of BPA with a diameter of about $2 \mu \mathrm{m}$. Higher reaction temperature used in DPP resulted in decreased particle diameter. However, DPP could cause unstable polymerization because of the loss of solvent. To overcome the limitations, Sellergren ${ }^{39}$ proposed reflux precipitation polymerization (RPP) at $90{ }^{\circ} \mathrm{C}$ with constant volume of the solvent during the polymerization to generate uniform MIPs. After $2 \mathrm{~h}$ of reaction at high temperature, the MIPs were quite uniform with a diameter of $2.0 \pm 0.2 \mu \mathrm{m}$. When comparing precipitation polymerization at $60{ }^{\circ} \mathrm{C}$ for $24 \mathrm{~h}$ and DPP under reflux condition for $3 \mathrm{~h}$, the yields were comparable.

For the above mentioned several kinds of precipitation polymerization methods, living precipitation polymerization can improve the dispersion of MIPs, but additional polymerization reagents like RAFT agents are needed. DPP and RPP can shorten the polymerization time, but higher polymerization temperature is needed. Furthermore, more complicated reaction devices are needed. So DPP and RPP have not been widely used. Traditional precipitation polymerization is still the most widely used method because of its simple operation. It should be noted that precipitation polymerization needs a large amount of organic solvents, which brings about environmental pollution and increases the cost. The polymer yield is low due to the low concentration of monomers.

\subsection{Spherical MIPs by emulsion polymerization}

Typically, SPE packing materials prefer particle sizes of several micrometers. The size of MIPs prepared by precipitation polymerization is below $5 \mu \mathrm{m}$, which is generally not suitable for 
filling SPE columns. Suspension polymerization ${ }^{40-42}$ can be used to prepare spherical MIPs with suitable large size for SPE. Oil-soluble polymerization system was dispersed in the water phase for polymerization. In order to stabilize the polymer droplets, dispersants were added. For example, Lenain ${ }^{40}$ prepared MIPs by suspension polymerization for SPE procedure. $80 \%$ of the MIP particles were situated in the $12-58 \mu \mathrm{m}$ range with an average diameter of $30 \mu \mathrm{m}$. In recent years, suspension polymerization has been less used because the surfactant would behave as an additional pollutant in the preparation process.

Pickering emulsion polymerization can be employed to prepare spherical MIPs with diameters of about $100 \mu \mathrm{M}$, which are suitable as SPE sorbents. Pickering emulsion is stabilized by solid particles, which are located at the interface between the two immiscible liquids, preventing coalescence of the emulsion droplets. The important step for Pickering emulsion polymerization is to form stable Pickering emulsions. So the choice of nanoparticles is crucial. Hydrophilic particles tend to form oilin-water emulsions while hydrophobic particles lead to the opposite situation. Until now, silica, ${ }^{4-53} \mathrm{Fe}_{3} \mathrm{O}_{4}$ particles, ${ }^{54-59}$ chitosan, ${ }^{60-62}$ halloysite nanotubes, ${ }^{54-56,63}$ Janus hydroxyapatite NPs, ${ }^{64,65} \mathrm{BHb},{ }^{66}$ yeast,${ }^{67}$ lignin, ${ }^{68}$ fluorescent NPs, ${ }^{69}$ etc., were adopted to stabilize Pickering emulsions for preparation of MIPs. Different particles enjoy different advantages. For example, silica nanoparticles are commonly used due to the stability, economy, and easy removal by HF etching. Pickering emulsion based on $\mathrm{Fe}_{3} \mathrm{O}_{4}$ particles can fabricate magnetic MIPs, which could be easily collected and separated. Chitosan is suitable as a stabilizer for Pickering emulsion polymerization due to its biocompatibility, environmental friendliness and low cost. Due to high mechanical strength, thermal stability, biocompatibility and abundance, halloysite nanotubes have been used for constructing polymer nanocomposites.

After formation of a stable Pickering emulsion, polymerization can be initiated to form polymers. Generally speaking, the polymerization was carried out in the dispersed phase, and finally spherical polymers were formed. ${ }^{43-51}$ The solid particles which are stable in the Pickering emulsion can be removed ${ }^{49,50}$ or remain ${ }^{54,55}$ on the polymer surface. The template molecules inside the polymer are removed to form MIPs. Generally, MIP microspheres obtained by Pickering emulsion polymerization are spherical with good dispersion, and particle size is generally about tens of microns. Frankly speaking, the polymer particle size is too large, and the recognition sites in the interior are difficult to use. In order to make the recognition sites on the MIP surface, Ye and his group ${ }^{49,50}$ proposed new Pickering polymerization methods using template molecules bonded to silica nanoparticles as stabilizer. After the silica nanoparticles were removed by HF solution, a permeable layer was obtained. All binding sites were located on the surface of MIPs, which is convenient for fast template binding.

Ye and his group ${ }^{43}$ also explored the preparation of watercompatible MIPs by oil-in-water Pickering emulsion polymerization using propranolol as a model template, MAA as functional monomer and EGDMA as cross-linker, denoted as MIPs-P. For comparison, MIP particles were also synthesized using traditional bulk polymerization, denoted as MIPs-B. The amount of water adsorbed by MIPs-P was 1.40 times higher than that by MIPs-B, whereas the amount of toluene adsorbed by MIPs-P was only $15.6 \%$ of that by MIPs-B. They attributed this phenomenon to the functional monomer of MAA. Because of the solubility of MAA both in the oil and in the water phase, MIPs-P have abundant surface carboxyl groups and therefore a hydrophilic surface. This new surface characteristic allowed the MIPs to recognize the template molecule with high selectivity in pure water. Water-in-oil Pickering emulsion also was adopted to prepare water-compatible MIP hydrogel. ${ }^{53,55}$ The water phase contained the template and the hydrophilic monomers polymerized to form MIPs. The key step was to obtain a stable prepolymerization complex, as water may disrupt the interactions between template and monomer molecules through competitive hydrogen bonding. For example, Agrofoglio ${ }^{52}$ synthesized MIP hydrogel by oil-in-water Pickering emulsion for controlled release of adenosine 5-monophosphate. To obtain a stable prepolymerization complex, 2-(dimethylamino)ethyl methacrylate and $N$-isopropylacrylamide were selected as monomers providing ionic interactions with anionic phosphate moiety of 5-monophosphate. From the above examples we can see that the research work concerning MIPs obtained by Pickering emulsion polymerization mainly focused on Ye's group. This may be due to the following reasons. First, a stable Pickering emulsion polymerization system is difficult to control, which requires rich experience. Second, the larger particle size leads to low adsorption capacity, which means that MIPs obtained by Pickering emulsion polymerization do not display obvious advantages in sample pretreatment or sensor construction.

\subsection{Spherical MIPs with polymer brush}

It is often necessary to detect a target in aqueous media, such as environmental water samples, beverages, and biological fluids. To achieve aqueous media recognition, inorganic MIPs based on the sol-gel process or PDA can be employed. For organic MIPs, surface hydrophilicity modification is necessary. Zhang ${ }^{70-79}$ proposed a strategy to graft hydrophilic polymer brush on the surface of spherical MIPs. Generally, spherical MIPs were first prepared by living precipitation polymerization $\left(\operatorname{RAFTPP}^{71,73,74}\right.$ or $\mathrm{ARTPP}^{72}$ ), then hydrophilic polymer brushes were grown in situ on their surfaces by surface initiated living polymerization. For example, Zhang prepared MIPs with PHEMA brush by ATRPP under ambient temperature with UV light, as shown in Fig. 3A. ${ }^{72}$ Fig. 3Ha shows the obtained spherical MIPs were narrow or monodisperse. It should be noted that from the SEM images, the differences between MIPs with or without polymer brush could not be observed. Grafting hydrophilic polymer brushes has been widely used in many situations, such as grafting hydrophilic polymer brushes on the surface of fluorescent MIPs (Fig. 3B), ${ }^{76,78}$ grafting hydrophilic temperature-responsive PNIPAAm brushes on the surface of photo-responsive MIPs to produce multi-responsive MIPs (Fig. 3C), ${ }^{71,75}$ in situ growth of magnetic microspheres on hydrophilic polymer brushes to prepare monodispersed hydrophilic and magnetic MIPs (Fig. 3D) (the TEM image shown in Fig. $3 \mathrm{Hb}$ confirmed the successful anchor 


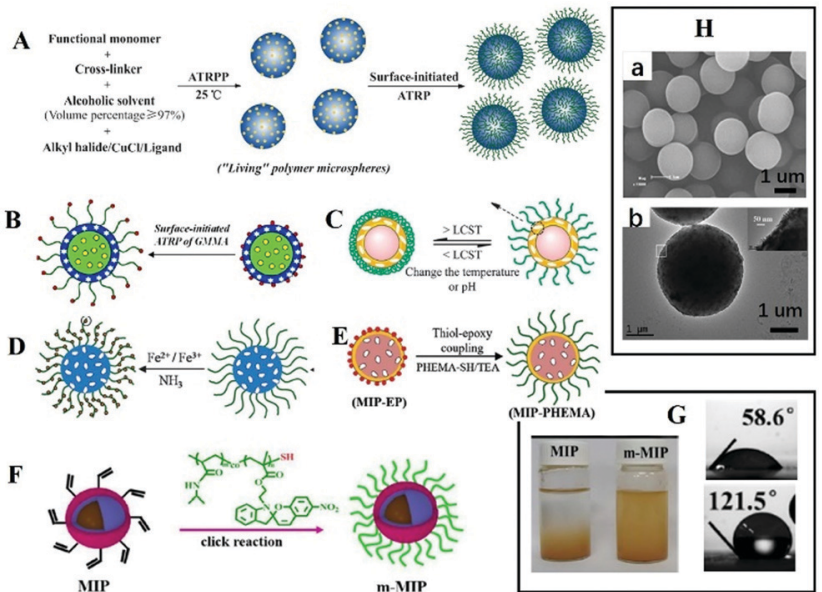

Fig. 3 Representation of MIPs with polymer brush. (A) A scheme for preparation of spherical MIPs with polymer brushes by living polymerization, adapted from ref. 72, Copyright 2012. (B) Fluorescent MIPs with brush, adapted from ref. 77, Copyright 2016 American Chemical Society. (C) Multi-responsive MIPs, adapted from ref. 71, Copyright 2012. (D) Magnetic MIPs with brush, adapted from ref. 74, Copyright 2014. (E) Preparation of MIPs with brush by thiol epoxy coupling, adapted from ref. 79, Copyright 2019 (F) Polymer brush by click reaction, adapted from ref. 81, Copyright 2020 American Chemical Society. (H) Images of MIPs with polymer brush ((a) adapted from ref. 78, Copyright 2012; and (b) adapted from ref. 74, Copyright 2014). (G) The water contact angle and the dispersity of MIPs in water, adapted from ref. 81, Copyright 2020 American Chemical Society.

of magnetic microspheres) $)^{74}$ or the preparation of biological sample-compatible MIPs by combining RAFT polymerization and thiol-epoxy coupling chemistry (Fig. 3E) ${ }^{79}$ In our previous work, ${ }^{80}$ water-compatible MIPs with PHEMA brush were prepared and employed as sorbent for extraction of four triazines from aqueous media. Surface grafting of polymer brush is a general approach for hydrophilic modification of MIPs.

Polymer brushes also can be grafted to MIPs by click reaction. Wang's group ${ }^{81}$ prepared magnetic core-shell MIPs, then grafted them with macromolecular chains by a "click reaction" to obtain hydrophilic MIPs. The obtained MIPs displayed excellent binding capacity and selectivity in aqueous solution (Fig. 3F). The static water contact angle decreased from $121.5^{\circ}$ to $58.6^{\circ}$, and the modified MIPs could be dispersed in water, as shown in Fig. 3G. Polymer brushes "grafted from" the surface of MIPs can be completed by a one-pot method, which is simple. Grafting polymer brushes to the surface of MIPs requires three independent steps involving the preparation of polymer brushes and MIPs, which is relatively cumbersome. However, the structure of polymer brushes can be changeable.

\subsection{Restricted access material MIPs (RAM-MIPs)}

Macromolecules existing in complicated sample matrices would adsorb on the surface of MIPs and hinder the specific recognition of targets. Restricted access materials (RAM) are a kind of sorbent containing hydrophilic functional groups and/or proteins on their external surface, which could exclude macromolecules. As shown in Fig. 4A, there are three kinds of RAM, namely internal surface phase, semipermeable surface phase and
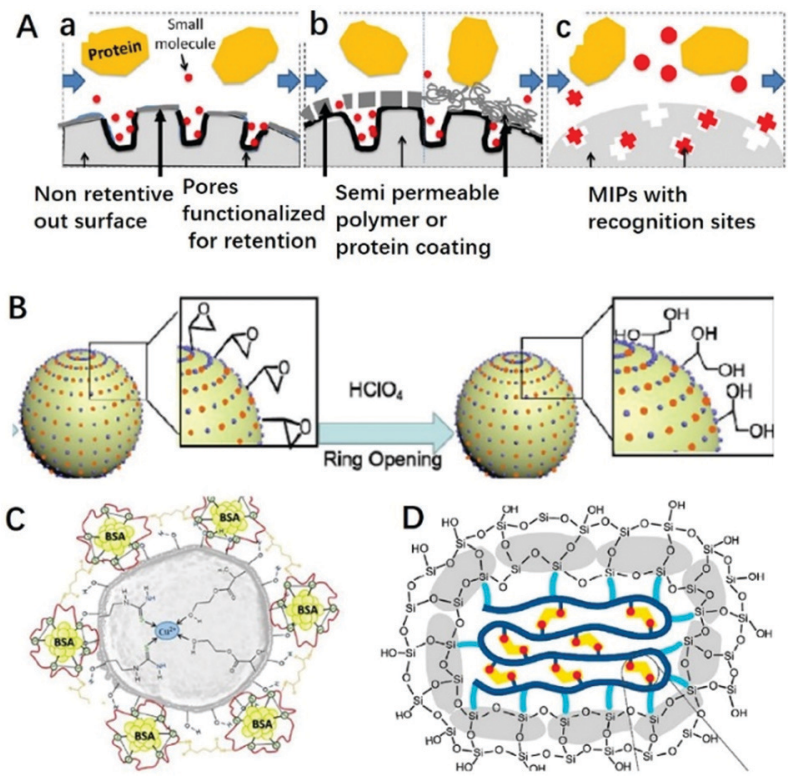

Fig. 4 Different classifications of RAM (A) include (a) internal surface, (b) semi-permeable surface (including both polymeric and protein-based hybrids), and (c) MIP phases, adapted from ref. 82, Copyright 2013 John Wiley and Sons. (B) RAM based on GMA ring opening, adapted from ref. 85 , Copyright 2020 Elsevier. (C) RAM based on protein BSA, adapted from ref. 89, Copyright 2018 Elsevier. (D) RAM based on $\mathrm{SiO}_{2}$ layer, adapted from ref. 93, Copyright 2019 American Chemical Society.

MIP RAM, and macromolecules could be excluded by a physical or chemical diffusion barrier. The physical diffusion barrier is based on the size of the pore and the chemical diffusion barrier depends on functional groups with selective retention. ${ }^{82}$ Combining these two types of RAM with MIPs, RAM-MIPs could effectively avoid the interference of macromolecules in purification or detection. Modification of hydrophilic hydroxyl groups on MIP surfaces is a common method to prepare RAM-MIPs, and glycidyl methacrylate (GMA) or KH-560 containing active epoxy groups is a commonly used copolymerization functional monomer. ${ }^{83-88}$ When the epoxy groups were hydrolyzed to produce a large amount of hydroxyl groups, the surface of MIPs were hydrophilic and the interference of biological macromolecules could be eliminated, as shown in Fig. 4B. For example, Gong prepared RAM-M-MIPs using GMA as co-monomer for magnetic-solid phase extraction (MSPE) of tetracyclines from untreated milk and egg samples. ${ }^{88}$ The obtained RAM-M-MIPs can effectively eliminate the interference of protein macromolecules with an exclusion rate of $99.4 \%$.

A protein like bovine serum albumin (BSA) also can be coated onto MIPs using glutaraldehyde as a cross-linker to prepare RAM-MIPs-BSA. Due to the electrostatic repulsion between the proteins in samples and the BSA layer fixed on the MIP surface (both negatively charged), $99 \%$ of the proteins from samples could be eliminated. ${ }^{89-92}$ For example, BSA was anchored on the surface of $\mathrm{Cu}(\mathrm{II})$ imprinted MIPs in order to provides better performance towards application in aqueous medium, ${ }^{89}$ as shown in Fig. 4C. In order to anchor BSA, HEMA was used as co-functional monomer to provide hydroxyl groups. 
When comparing IIPs, IIPs-HEMA, IIPs-HEMA-BSA was the most efficient polymer for simultaneous $\mathrm{Cu}^{2+}$ preconcentration and BSA protein exclusion in aqueous medium. Gong ${ }^{90}$ prepared core-shell RAM-MIPs-BSA for SPE of ofloxacin and enrofloxacin from bovine serum. The maximum adsorption capacity of RAM-MIPs-BSA was $50.55 \mathrm{mg} \mathrm{g}^{-1}$ for ofloxacin, with a $99.4 \%$ protein exclusion rate.

Chang ${ }^{93}$ prepared $\mathrm{SiO}_{2}$-coated MIPs for the adsorption of BPA, as shown in Fig. 4D. The anchored $\mathrm{SiO}_{2}$ clusters confined the conformation of the copolymer, suppressed the nonspecific hydrophobic interactions and enhanced the water compatibility of MIPs. With the help of the $\mathrm{SiO}_{2}$ layer, the hydrophobic MIP particles could well disperse in aqueous solution. Furthermore, nonspecific hydrophobic interaction was reduced resulting in high adsorption kinetics and an outstanding imprinting effect, including an imprinting factor of 14 , adsorption capacity of $40.3 \mathrm{mg} \mathrm{g}^{-1}$, and selectivity factor of 24 .

\section{Core-shell structured MIPs}

The recognition sites in irregular or solid spherical MIPs are difficult to utilize due to the high mass transfer resistance. In order to reduce the resistance of mass transfer and improve the utilization rate of recognition sites, surface imprinting was developed to prepare core-shell structure MIPs. Surface imprinting usually involves the following three steps: first, preparation of a supporting matrix, then surface modification of the supporting matrix, and finally coating an organic or inorganic MIP layer on the surface of the supporting matrix. Surface modification is the key step for preparation of coreshell MIPs. The diverse surface modification methods are emphasized in the following section. The core-shell structure MIPs can be divided into solid core with solid shell, solid core with mesoporous shell, hollow core with solid shell, hollow core with mesoporous shell etc. In this section, only MIPs with solid core and solid shell structure are discussed, and the others will be discussed with hollow MIPs or mesoporous MIPs.

\subsection{The cores for core-shell MIPs}

Many solid particles, like $\mathrm{SiO}_{2}$ nanoparticles, ${ }^{94-97}$ mesoporous $\mathrm{SiO}_{2},{ }^{98-100}$ chitosan, ${ }^{101}$ metal-organic frameworks (MOFs), ${ }^{102-107}$ PtPd nanoflowers, ${ }^{108} \mathrm{TiO}_{2},{ }^{109,110}$ polymers like $\mathrm{PS}^{111}$ and PMMA,${ }^{112}$ fluorescent nanoparticles (FNPs), ${ }^{113-115} \mathrm{Fe}_{3} \mathrm{O}_{4}$ magnetic nanoparticles (MNPs), ${ }^{116-149}$ etc., have been used as a supporting matrix. Silica nanoparticles are widely used to prepare core-shell structure MIPs because of their simple preparation and good stability. Mesoporous silica, like FDU- $12^{98}$ and SBA-15, ${ }^{100}$ with large and ordered pore sizes, higher surface area and wellmodified surface properties, also has been widely used. MNPs also have been widely used due to their magnetic separation ability. The advantages of hydrophilicity, biocompatibility and non-toxicity make chitosan suitable for imprinting. MOFs such as MOF-5, ${ }^{103}$ UiO-66- $\mathrm{NH}_{2},{ }^{104}$ MOF-177, ${ }^{105}$ and MIL-101 ${ }^{106}$ with tunable pore structure are often employed to prepare MOF@MIPs for separation, biosensors and drug delivery. Using fluorescent nanoparticles such as quantum dots (QDs) ${ }^{113}$ and carbon dots $(\mathrm{CDs})^{115}$ as cores to prepare core-shell structured MIPs can produce fluorescence sensors. The core-shell MIPs using $\mathrm{TiO}_{2}$ as core can achieve highly efficient photocatalytic degradation of target pollutants under visible light irradiation. According to the required application, the appropriate core materials can be selected.

\subsection{Surface modification of cores}

The key point for the preparation of core-shell MIPs lies in the growth of the MIP layer on the surface of the solid core, rather than nucleation in solution. Therefore, surface modification is necessary. Taking magnetic microspheres as an example, several surface modification methods are summarized in Fig. 5. Before introducing the surface modification methods of MNPs, it is necessary to introduce the preparation methods of MNPs. $\mathrm{Fe}_{3} \mathrm{O}_{4}$ MNPs can be prepared by the coprecipitation $\operatorname{method}^{116,117}$ or the solvothermal method. ${ }^{124-128}$ The MNPs prepared by coprecipitation were hydrophilic with size of about $10 \mathrm{~nm}$ and relatively weak magnetic properties. The MNPs prepared by the solvothermal method were about $500 \mathrm{~nm}$ with stronger magnetic property.

In order to transform hydrophilic MNPs into hydrophobic MNPs, they were modified with polyethylene glycol (PEG) ${ }^{116,117}$ or oleic acid (OA), ${ }^{118-122}$ then were coated into MIPs by suspension polymerization ${ }^{118,122}$ or Pickering emulsion polymerization. ${ }^{60}$ For this kind of magnetic MIPs (M-MIPs), serval magnetic microspheres were coated into one MIP particle, as multiple core in one shell. The third was to introduce a thin $\mathrm{SiO}_{2}$ layer on the surface of the MNPs, and then an inorganic MIP layer was coated by the sol-gel process. ${ }^{123-125}$ The formed MIP layer may be a solid $\mathrm{SiO}_{2}$ layer ${ }^{123}$ or mesoporous $\mathrm{SiO}_{2}$ layer. ${ }^{125}$ The fourth was to coat a thin $\mathrm{SiO}_{2}$ layer and then introduce vinyl double bond on the surface of the MNPs, followed by coating an organic MIP layer by free radical polymerization. ${ }^{126-137}$ In order to fix more functional groups, the $\mathrm{SiO}_{2}$ layer on the surface of MNPs can be designed as a

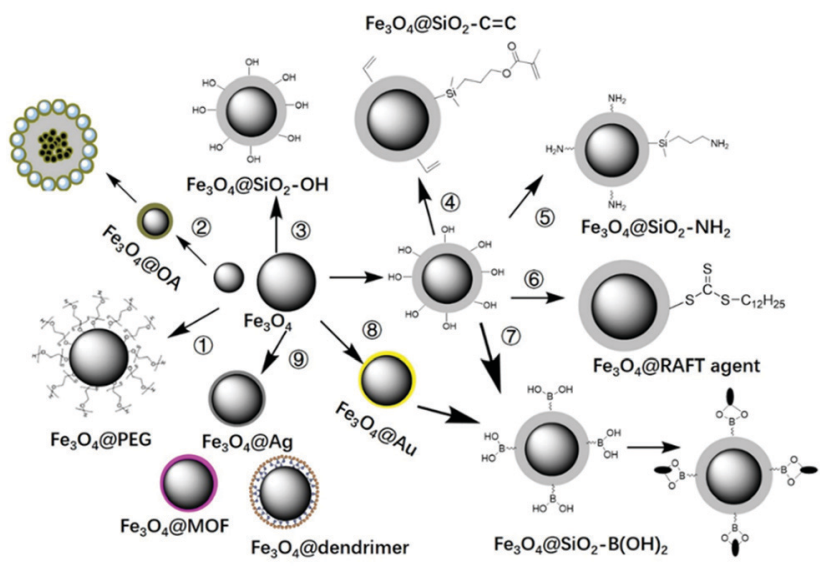

Fig. 5 Surface modification of MNPs with PEG, OA, TEOS, vinyl double bond, amino groups, RAFT agents, boronic acid, gold or silver NPs, MOF, etc. 
mesoporous silica layer. ${ }^{126-128}$ In order to make the recognition sites evenly distributed in the shell, the template molecules were fixed on the surface of cores. So amino groups ${ }^{138-142}$ or boronic acid ${ }^{137-150}$ were introduced into the surface of MNPs through APTES or phenylboronic acid, then templates were immobilized on the surface of MNPs, followed by the imprinted layer coating on the surface of magnetic microspheres. In order to facilitate the coating of the MIP layer on the core surface and effectively controlling the thickness of the shell, RAFT agents ${ }^{143-146}$ were introduced on the surface of MNPs, and the shell MIPs with controllable thickness were obtained by living polymerization. The above are general surface modification methods, which also can be used for surface modification of other solid particles.

In order to meet the requirements of different application fields, MNPs can be modified by other functional groups. For example, Zhang ${ }^{151}$ modified MNPs with poly(glycidyl methacrylate) for introduce boron-nitrogen (B-N) coordination, then further immobilized the template glycoproteins (ovalbumin, OVA). Finally, a redox-polymerized aniline imprinted layer was deposited onto the MNP surface. $\mathrm{Xie}^{152}$ used $\mathrm{TiO}_{2}$-functionalized MNPs as core to prepare M-MIPs. First, a $\mathrm{TiO}_{2}$ layer was deposited directly on the surface of the MNPs using a sol-gel method for immobilizing template phenylphosphonic acid by Lewis acidbase interaction. The noble metal gold $(\mathrm{Au})$ was used as a coating material to prepare M-MIPs to allow immobilizing the template with other useful species based on the Au-S bond. For example, Ma et al. ${ }^{149}$ coated an Au layer on the surface of MNPs in order to anchor 4-mercaptophenylboronic acid, then with further immobilization of glycoprotein before the imprinting process. To achieve surface-enhanced Raman spectroscopy detection of target, silver NPs were employed. ${ }^{153,154}$ Yu and co-workers coated $\mathrm{Ag}$ NPs on the surface of MNPs, and then coated MIPs on the surface of $\mathrm{Fe}_{3} \mathrm{O}_{4} @ A g .{ }^{154}$ In this work, MNPs were prepared by a solvothermal approach, and functionalized with amino groups. Then $\mathrm{Ag}$ NPs were located on the $\mathrm{Fe}_{3} \mathrm{O}_{4} @ \mathrm{SiO}_{2}-\mathrm{NH}_{2}$ surface via electrostatic interaction. Vinyl double bonds were modified on $\mathrm{Fe}_{3} \mathrm{O}_{4} @ \mathrm{Ag}$ to facilitate imprinting by free radical polymerization. Zhou first coated MOF ZIF-8 on the surface of MNPs, then prepared $\mathrm{Fe}_{3} \mathrm{O}_{4} @ Z$ ZIF-8@MIPs for selective adsorption of tetrabromobisphenol A from water samples. ${ }^{155}$ The MOF layer provided a large specific surface area and abundant pores, enabling a better adsorption effect.

The properties and morphology of M-MIPs can be affected by surface modification. He's group ${ }^{156}$ modified MNPs with APTES and KH-570 to get $\mathrm{Fe}_{3} \mathrm{O}_{4}-\mathrm{NH}_{2}$ and $\mathrm{Fe}_{3} \mathrm{O}_{4}-\mathrm{CH}_{2}=\mathrm{C}_{2} \mathrm{H}_{4}$, and then prepared M-MIPs. $\mathrm{Fe}_{3} \mathrm{O}_{4}-\mathrm{CH}_{2}=\mathrm{C}_{2} \mathrm{H}_{4} @$ @MIPs exhibited more regular shapes and better dispersibility compared to $\mathrm{Fe}_{3} \mathrm{O}_{4}{ }^{-}$ $\mathrm{NH}_{2} @$ @IPs. The saturation magnetization of $\mathrm{Fe}_{3} \mathrm{O}_{4}-\mathrm{NH}_{2} @$ @MIPs (23.25 emu g ${ }^{-1}$ ) was higher than that of $\mathrm{Fe}_{3} \mathrm{O}_{4}-\mathrm{CH}_{2}=\mathrm{C}_{2} \mathrm{H}_{4} @ M I P s$ $\left(18.63 \mathrm{emu} \mathrm{g}^{-1}\right)$, which may be attributed the poor dispersibility of $\mathrm{Fe}_{3} \mathrm{O}_{4}-\mathrm{NH}_{2}$. Therefore, it is very important to choose a suitable surface modifier. Armenta and co-workers ${ }^{157}$ discussed the effect of the MNP modifier used on the extraction performance of M-MIPs. They employed PEG and 3-(trimethoxysilyl)propyl methacrylate(v) to modify MNPs prepared by a co-precipitation method, then coated MIPs by bulk polymerization. The resulting V-MNPs were less prone to aggregation than PEG-MNPs and more V-MNPs were embedded into MIPs due to the presence of vinyl groups, which were able to participate in free radical copolymerization with other monomers. In the same way, the choice of MNPs also affects the morphology of M-MIPs. MNPs prepared by a coprecipitation method are easy to agglomerate, and the prepared M-MIPs prefer to be agglomerated. MNPs prepared by a solvothermal method have large particle size and good dispersion, and the prepared M-MIPs also have good dispersion, and core-shell structure can be easily observed.

The surface imprinting process after surface modification is still based on free radical polymerization, sol-gel process or self-polymerization of dopamine. Those methods are relatively well known, so the process is not repeated here. It should be pointed out that the adhesion between core-shell MIP particles is a common phenomenon, so the preparation of monodisperse ultra-thin shells is a development direction in the future.

\section{Hollow MIPs (H-MIPs)}

A core-shell structure can improve the utilization of recognition sites of MIPs, but a target molecule can only enter the recognition site from the outer surface. If MIPs with a hollow structure (H-MIPs) were to be prepared, the target molecules can enter the recognition site from the inner and outer double surfaces, which is more efficient. Therefore, preparation of H-MIPs has become an important research direction in this field. As shown in Fig. 6, H-MIPs can be prepared by the sacrificial solid cores method, seed swelling polymerization, Pickering emulsion polymerization, and surface imprinting on hollow core.

\subsection{Sacrificial solid cores}

Inspired by core-shell MIPs, H-MIPs can be obtained by removing core materials. In this method, the step of removing cores is added on the basis of preparing core-shell MIPs, and selective etching is used to remove cores. Usually, $\mathrm{PS},{ }^{158,159} \mathrm{SiO}_{2},{ }^{160-169}$ mesoporous silica, ${ }^{170-173} \mathrm{~K}_{2} \mathrm{Ti}_{4} \mathrm{O}_{9},{ }^{174} \mathrm{CaCO}_{3}{ }^{175}$ and $\mathrm{Fe}_{3} \mathrm{O}_{4}$ @ $\mathrm{SiO}_{2}{ }^{176-179}$ are used as the sacrificial material to prepare H-MIPs. This method is widely used because both organic and inorganic H-MIPs can be prepared. $\mathrm{SiO}_{2}$ is commonly used as the sacrificial solid core because of its chemical stability and easy removal by HF etching. Fig. 7A and C show TEM and SEM images of H-MIPs after removal of $\mathrm{SiO}_{2}$ core. The shell is well preserved. When using PS as the core, the hollow MIP shell often collapses because the dissolution and removal of the PS core are accompanied by its swelling. In order to get an intact shell, the MIP shell has to be thick. $\mathrm{He}^{158}$ proposed an approach to prepare H-MIPs with thin and solid MIP shells. PS@SiO 2 particles were used as the core, and only the PS part was sacrificed. The $\mathrm{SiO}_{2}$ part kept in the H-MIPs made it possible to get a thin but solid MIP shell. The imprinted shell was estimated to be about $50 \mathrm{~nm}$. As shown in Fig. 7B, the H-MIPs were rigid and kept a perfect spherical shape without breakage and deformation. $\mathrm{Fe}_{3} \mathrm{O}_{4} @ \mathrm{SiO}_{2}$ also was used as 


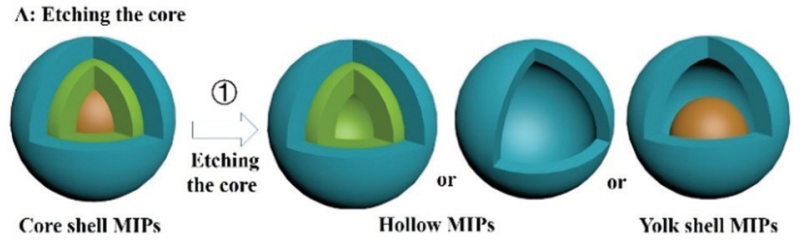

B: Seed swelling polymerization

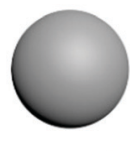

\section{(1)}

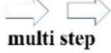
multi step
swelling

PS seed

$$
\begin{gathered}
\text { Seed swelling polymerization } \\
\text { Imprinting }
\end{gathered}
$$
Imprinting

C: Pickering emulsion polymerization

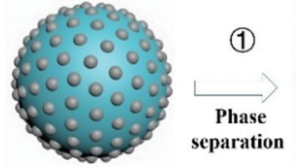

Pickering emulsion drop

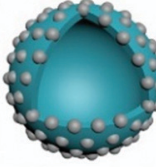

Hollow MIPs

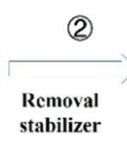
stabilizer core

D: Surface imprinting on hollow core
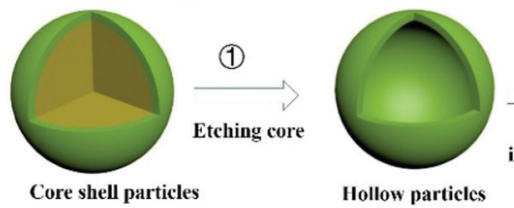

(2) Removal PS n

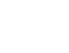

(

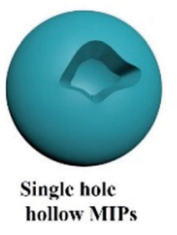
hollow MIPs

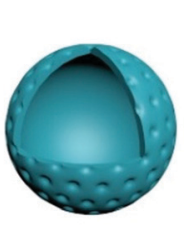

(2)
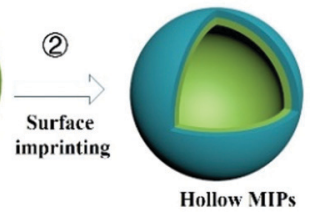

Fig. 6 The methods for preparation of hollow MIPs.

a sacrificial support to prepare yolk-shell magnetic hollow MIPs by etching the $\mathrm{SiO}_{2}$ layer with $\mathrm{HF}$ to form $\mathrm{Fe}_{3} \mathrm{O}_{4} @$ @void@MIPs, as shown in Fig. 7D. ${ }^{176}$ The yolk-shell structure is of great interest because it retains the magnetic separation ability and has hollow characteristics like high surface area, suitable pore size and low density. The exposed inner surface can overcome the defects caused by the high cross-linking of the molecular imprinting.

\subsection{Seed swelling polymerization}

H-MIPs also can be prepared by seed swelling polymerization, ${ }^{180-183}$ which was pioneered by our group in $2011 .{ }^{180}$ Monodispersed PS seed particles were first prepared by dispersion polymerization. Then PS was swelled, followed by polymerization on the surface of PS. Finally, the PS was washed to form the hollow polymers. In a typical multistep seed swelling polymerization process, PS particles were first swelled by dibutyl phthalate for $24 \mathrm{~h}$, followed by the second step of swelling by toluene, functional monomer, crosslinker, and template for another $24 \mathrm{~h}$. After the two swelling steps, the mixture was polymerized to get the single-hole hollow polymers, as shown in Fig. 7E and F. The formation mechanism of holes was based on the concomitant microphase separation and symmetrical volume shrinkage of shell materials, which can be broken down into five consecutive steps: (i) the formation of a prepolymer layer, (ii) the microphase separation of two polymer shell layers, (iii) the development of a small interior void in the shell, (iv) formation of a film-covered hole, and (v) formation of an open hole in the polymer shells. Using this seed swelling
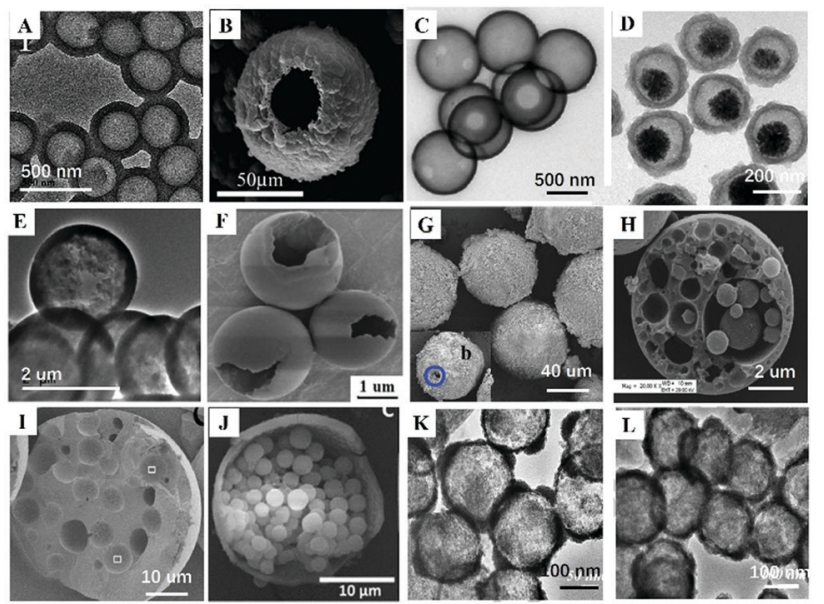

Fig. 7 Images of different H-MIPs. (A) TEM image of H-MIPs by etching $\mathrm{SiO}_{2}$ core, adapted from ref. 161, Copyright 2017. (B) TEM image of H-MIPs with thin shell by etching PS core with the protection of $\mathrm{SiO}_{2}$ layer, adapted from ref. 158, Copyright 2014. (C) SEM image of H-MIPs by etching mesoporous $\mathrm{SiO}_{2}$ core, adapted from ref. 171, Copyright 2012. (D) TEM image of $\mathrm{Fe}_{3} \mathrm{O}_{4}$ (avoid@MIPs by etching $\mathrm{SiO}_{2}$ layer, adapted from ref. 176, Copyright 2018, Elsevier. TEM (E) and SEM (F) images of H-MIPs prepared by seed swelling polymerization, adapted from ref. 180, Copyright 2011. (G) SEM image of H-MIPs prepared by Pickering emulsion polymerization, adapted from ref. 58, Copyright 2013, American Chemical Society. (H) SEM image of multi-hollow MIPs prepared by oil-in-water Pickering emulsion polymerization, adapted from ref. 185, Copyright 2015, John Wiley and Sons. (I) W-O-W Pickering emulsion polymerization, adapted from ref. 59, Copyright 2015 Elsevier. (J) SEM image of multi-core H-MIPs prepared by oil-in-water Pickering emulsion polymerization, adapted from ref. 51, Copyright 2018, Elsevier. TEM images of hollow $\mathrm{SnO}_{2}(\mathrm{~K})$ and hollow $\mathrm{SnO}_{2}$ based H-MIPs (L), adapted from ref. 186, Copyright 2018, Elsevier.

polymerization method, H-MIPs have been prepared for selective recognition of $N$-nitrosamine, ${ }^{181}$ triazines, ${ }^{182}$ and tetracycline. ${ }^{183}$

Multistep swelling before polymerization is complex and time-consuming. $\mathrm{Li}^{184}$ proposed miniemulsion polymerization to prepare single-hole H-MIPs for recognition of BPA. MAA was chosen as the hydrophilic functional monomer and EGDMA as the cross-linker. In the swelling process, the oil phase, including template, functional monomer, crosslinker and dibutyl phthalate, was added dropwise into the water phase composed of sodium lauryl diphenyl ether disulfonate under vigorous stirring to form monomer miniemulsion. The monomer miniemulsion was added dropwise to dispersion liquid of PS seed, followed by $12 \mathrm{~h}$ of swelling. During the polymerization process, an eccentric sphere structure with internal void was formed firstly, the surface pores and internal pores were increased by eluting PS seeds, and finally single-pore H-MIP particles were formed. The swelling process was observed by dynamic light scattering. The particle size of mono-disperse PS seed prepared by emulsion polymerization was $145 \mathrm{~nm}$ and the droplet sizes of monomer miniemulsion were $287 \mathrm{~nm}$. The size of PS seed after the miniemulsion swelling increased to $275 \mathrm{~nm}$. After polymerization, the size of the product was $269 \mathrm{~nm}$, which was a little smaller than the swelled seed due to the volume shrinkage during the polymerization. These microcapsules collapse into "bowl-like" shape with relatively 
low modulus of the shell polymer. The average thickness of the shell layer was about $28 \mathrm{~nm}$.

\subsection{Pickering emulsion}

The third method for preparing H-MIPs is Pickering emulsion polymerization. In Section 2 we discussed that solid-sphere MIPs could be prepared by Pickering emulsion polymerization. More solvent is used to prepare H-MIPs than solid-sphere MIPs, and the hollow structure stems from phase separation. Furthermore, the shell of the H-MIPs is semipermeable, arising from the particle interstices, and the permeability can be modulated by changing the particle size and morphology. For example, $\operatorname{Pan}^{59}$ prepared M-H-MIPs for adsorption of l-cyhalothrin using Pickering emulsion polymerization stabilized by halloysite nanotubes and a few hydrophilic $\mathrm{Fe}_{3} \mathrm{O}_{4}$ nanoparticles. The Pickering emulsion polymerization was carried out between St and functional monomer 4-VP in the presence of toluene solvent. The cross-linked polymer network tended towards phase separation in the poor solvent, toluene, driven by the interfacial tension and precipitation at the interface. By elution with water and ethanol, hollow structures were readily formed by the removal of the residual toluene and unreacted 4 -VP. The hollow structure can be observed and confirmed by optical micrographs of the MIPs. The emulsion droplets exhibited a spherical hollow structure without collapse, and the hollow structures existed in the MIPs after elution with asymmetric and nonuniform capsule shells with a thickness range of 7.0-20 $\mu \mathrm{m}$. Because solid particles were used as stabilizer, the surface of H-MIPs was rough and those solid particles can be observed under high-resolution SEM, as shown in Fig. $7 \mathrm{G}$.

Using a water in oil in water (w1/o/w2) Pickering emulsion, multi-hollow MIPs also can be prepared. For example, Pan and co-workers $^{62}$ synthesized multi-hollow M-MIPs using w1/o/w2 Pickering emulsion. The inner water in oil (w1/o) droplets were stabilized by hydrophobic $\mathrm{Fe}_{3} \mathrm{O}_{4}$ NPs, and the outer oil in water $(\mathrm{o} / \mathrm{w} 2)$ phase was stabilized by cellulose nanocrystals. The template and functional monomer were contained in the oil phase. After polymerization in the oil phase, multi-hollow holes stemming from the inner water phase were distributed uniformly inside the MIPs, as shown in Fig. 7I. Feng ${ }^{185}$ prepared multi-hollow M-MIPs by incorporating 3-indolebutyric acid and ferroferric oxide nanoparticles simultaneously into a poly(styrene-co-methacrylic acid) copolymer (poly(St-co-MAA)) matrix for the selective enrichment of indolebutyric acid. Firstly, MNPs and poly(St-co-MAA) were each prepared. Then MNPs, template 3-indolebutyric acid, and poly(St-co-MAA) were added into chloroform solvent. And then the mixture was transferred into $10 \mathrm{~mL} \mathrm{NaOH}$ solution under vigorous stirring at room temperature. After $1 \mathrm{~h}$, the chloroform was removed by heating under stirring. After cooling to room temperature, the products were collected, purified and dried. Lots of pores with sizes of $0.2-4 \mu \mathrm{m}$ can be observed on the surface of the obtained MIPs with size around $10 \mu \mathrm{m}$, as shown in Fig. $7 \mathrm{H}$. However, the preparation and hole formation mechanism was not discussed in that work. The multi-hollow holes may stem from the removal of chloroform.
Using Pickering emulsion polymerization, $\mathrm{Li}^{51}$ prepared H-MIPs with multiple cores for recognition of BPA, as displayed in Fig. 7J. The formation of the hollow structure was attributed to the polymerization-related phase separation and interfacial tensions. The formation of multicore structure could be due to BPA precipitation nucleation. In this polymerization system, 4-VP and DVB were functional monomer and crosslinker, respectively, while hexadecane was employed as solvent. Because of the poor solubility of BPA in hexadecane, BPA precipitated from the oil phase, and played the part of nucleating agent in the phase separation process of the propagating copolymers. The gradual deposition of polymer on the nuclei finally resulted in the formation of multicore structured hollow spheres. This method is not universal because it has high requirements for the solubility of template molecules and solvents.

\subsection{Surface imprinting on hollow cores}

H-MIPs also can be prepared by surface imprinting on the hollow cores, like hollow $\mathrm{SnO}_{2},{ }^{186}$ hollow mesoporous silica, ${ }^{187,188}$ hollow $\mathrm{Fe}_{3} \mathrm{O}_{4},{ }^{130}$ hollow Ag NPs, ${ }^{189}$ etc. For the sacrificial solid cores method, the recognition sites would be destroyed in the longterm etching process. This process can be avoided by using surface imprinting on the hollow cores. For example, Tan ${ }^{130}$ prepared M-H-MIPs by wrapping MIP layer on the surface of hollow magnetic $\mathrm{Fe}_{3} \mathrm{O}_{4}$, which was prepared via a one-pot hydrothermal method. When compared with solid $\mathrm{Fe}_{3} \mathrm{O}_{4}$ microspheres, hollow $\mathrm{Fe}_{3} \mathrm{O}_{4}$ displays many advantages, like uniform particle size, lower density, higher specific surface area, and excellent dispersibility in aqueous phase, making it well dispersed in the next polymer-coating processes. Jia ${ }^{184}$ prepared H-MIPs by a surface imprinting method using hollow $\mathrm{SnO}_{2}$ as support for selective recognition and separation of luteolin. First $\mathrm{SiO}_{2} @ \mathrm{SnO}_{2}$ was prepared, and the $\mathrm{SiO}_{2}$ was etched to form hollow $\mathrm{SnO}_{2}$ (Fig. 7K). Then H-MIPs (Fig. 7L) were prepared by living ATRP on the surface of hollow $\mathrm{SnO}_{2}$. $\mathrm{Yu}^{185}$ prepared H-MIPs by surface imprinting on hollow silica mesoporous microspheres. First hollow silica mesoporous microspheres were prepared and modified with APTES and acryloyl chloride. Then MIP layer was coated on the surface of the hollow silica mesoporous microspheres using AA as functional monomer, EGDMA as crosslinker and tetradifon as template. After the original hollow silica mesoporous microspheres were removed by HF, the shell morphology still remained intact.

Among the four kinds of method, the method of etching cores is widely used because both organic and inorganic H-MIPs could be prepared and the particle size could be adjusted by adjusting the size of cores. Surface imprinting on hollow cores is similar to the etching of cores. Big hollow MIPs with particle size suitable for SPE could be prepared by the seed swelling polymerization method. However, hollow MIPs with thin shell are hard to control. Moreover, multi-swelling is time consuming. Only few H-MIPs have been prepared by Pickering emulsion polymerization, maybe because of the big particle size and relatively low binding capacity. 


\subsection{M-H-MIPs}

M-MIPs often use MNPs as core, and hollow MIPs often sacrifice the cores. Fortunately, magnetic hollow MIPs (M-H-MIPs) can be prepared by in situ growth on the surface of H-MIPs. ${ }^{190-192}$ In our previous work, ${ }^{190}$ we prepared M-H-MIPs for selective enrichment of atrazine by in situ growth of MNPs on the surface of H-MIPs. First, H-MIPs were prepared by multi-step swelling polymerization (which was discussed in Section 4.2). To facilitate the growth of MNPs on the surface of H-MIPs, GMA was used as a co-functional monomer, which offers potential hydroxyl groups on the surface of H-MIPs for in situ growth of $\mathrm{Fe}_{3} \mathrm{O}_{4}$ NPs. Epoxy bond opening provided abundant hydroxyl groups on the surface of H-MIPs, on which $\mathrm{Fe}_{3} \mathrm{O}_{4}$ was prior grown. Then, under base medium in a $\mathrm{N}_{2}$ atmosphere, $\mathrm{Fe}_{3} \mathrm{O}_{4}$ was grown in situ based on the cooperation of $\mathrm{Fe}^{3+}$ and $\mathrm{Fe}^{2+}$. Chen ${ }^{191}$ prepared M-H-MIPs for specific extraction of protocatechuic acid using a similar method. The difference is that H-MIPs were prepared using mesoporous silica spheres (MCM-48) as sacrificial support. From the above reference we can see that to achieve successful in situ growth of $\mathrm{Fe}_{3} \mathrm{O}_{4}$ NPs, GMA was necessary as co-functional monomer because $\mathrm{Fe}_{3} \mathrm{O}_{4}$ NPs can be chemisorbed onto PGMA by forming five-membered chelate rings with the Fe atoms. ${ }^{192}$

\section{Mesoporous MIPs}

Mesoporous MIPs were developed from mesoporous silica. Mesopores have diameters between 2 and $50 \mathrm{~nm}$ according to the IUPAC classification. Due to the large specific surface area and high adsorption capacity of mesoporous MIPs, they are widely used in separation, adsorption and chemical sensors. Mesoporous MIPs can be divided into homogeneous mesoporous, core-shell mesoporous, hollow mesoporous and multilevel mesoporous MIPs depending on the morphology.

\subsection{Homogeneous mesoporous MIPs}

5.1.1 Surface imprinting in the pores of mesoporous silica. Generally, mesoporous MIPs can by prepared by the surface imprint grafting method and one-pot synthesis method, as shown in Fig. 8. For a typical surface imprint grafting method, mesoporous silica is first prepared, and then MIP layers are grafted in the mesopores. For example, $\mathrm{Xu}^{193}$ prepared 2D MIPs in the pores of SBA-15 for recognition of cholesterol. In this $2 \mathrm{D}$ imprinting strategy, only functional monomer was used while crosslinker was not employed. Functional monomers were anchored on the walls of pores of SBA-15, ensuring that the functional monomers were moveable and the recognition sites were flexible. To anchor functional monomer, click reaction was employed, with azide-modified $\beta$-cyclodextrin (azide- $\beta$-CD) as the functional monomer and alkynyl-modified SBA-15 (alkyne-SBA-15) as the skeleton. Template-monomer complexes were first formed by assembly of azide- $\beta$-CD molecules with template, and then the functional monomers were anchored to the walls of the SBA-15 via click chemistry. The BrunauerEmmett-Teller (BET) surface areas of SBA-15 and MIPs were

\section{A: Surface imprint grafting method}

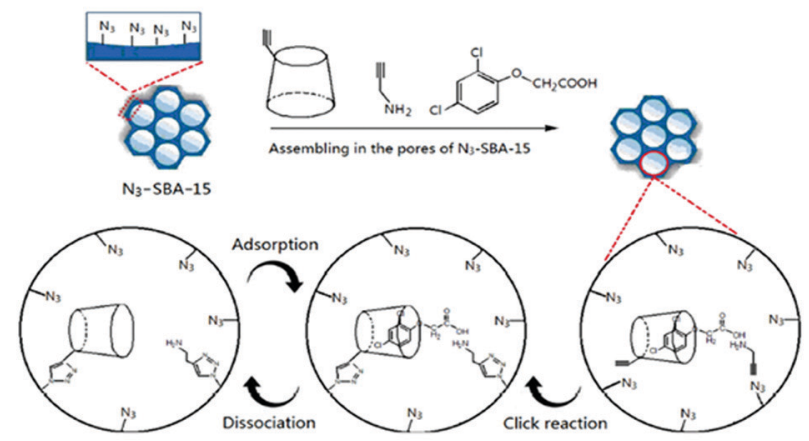

B: One pot synthesis method

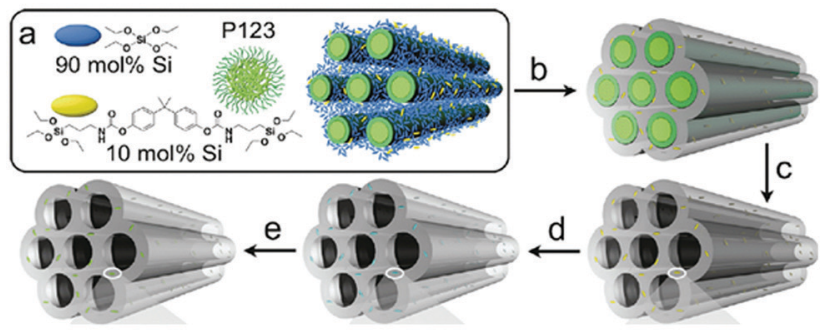

C: Dual template one pot synthesis method

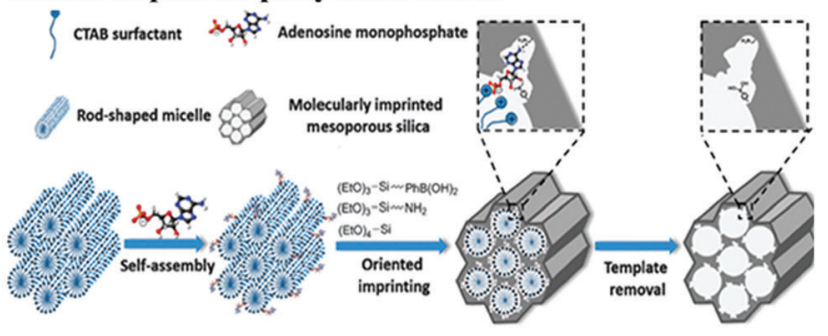

Fig. 8 Representation of preparation of homogeneous mesoporous MIPs. (A) 2D Imprinting in the pores of mesoporous silica by click reaction, adapted from ref. 194, Copyright 2019, Elsevier. (B) One-pot synthesis method for formation of mesoporous MIPs using P123 as soft template for mesopores, adapted from ref. 195, Copyright 2011, American Chemical Society. (C) Dual-template docking oriented molecular imprinting method, adapted from ref. 204, Copyright 2015.

553 and $417 \mathrm{~m}^{2} \mathrm{~g}^{-1}$, respectively. The pore diameters of SBA-15 and MIPs were 10.1 and $8.4 \mathrm{~nm}$, respectively. The pore volumes of SBA-15 and MIPs were 1.14 and $0.87 \mathrm{~cm}^{3} \mathrm{~g}^{-1}$, respectively. The above data confirmed that the ordered mesoporous structure was well preserved after 2D imprinting. Similarly, the same team also grafted 2D imprinted layer in SBA-15 pores for recognition of 2,4-D, as displayed in Fig. 8A, ${ }^{194}$ using a similar process. To facilitate click reaction, SBA-15 and functional monomer $\beta$-CD were modified with azide groups and alkyne groups respectively. The TEM images of SBA-15 (Fig. 9A) and MIPs (Fig. 9B) confirmed the well-preserved ordered mesoporous structure. It should be noted that the selectivity of recognition sites formed by $2 \mathrm{D}$ imprinting was worse than that of sites formed by 3D imprinting. However, 3D imprinting in the pores of mesoporous silica is hard to control because mesoporous channels are easily blocked. Therefore, the strategy of imprinting inside the mesoporous channels is rarely used. 
5.1.2 One-pot formation of mesoporous MIPs. Grafted MIP layers can block pores or decrease their diameters significantly. The one-pot preparation method in which the mesoporous pores and recognition sites are formed during the polymerization process simultaneously is relatively simple. Generally, a soft template was employed to form mesoporous structure. ${ }^{195-202}$ Wall thicknesses were typically between 3 and $8 \mathrm{~nm}$, and particle sizes were easily tuned. By adjusting the synthetic conditions and starting materials, the diameters of mesoporous pores can range from $3 \mathrm{~nm}$ to tens of nanometers. The pore structure of SBA-15 mesoporous silica was templated by a nonionic block copolymer surfactant template (triblock copolymer Pluronic P123), ${ }^{195,196}$ while MCM-41 with tunable pore size ranging from 2 to $10 \mathrm{~nm}$ was templated by the surfactant CTAB. ${ }^{197-200}$ Fig. 9C and D display the TEM images of SBA-15- and MCM-41-based Ni(II) ion imprinted polymers. ${ }^{201}$ The surface of mesoporous structure of MIPs was rough while the non-mesoporous structure of MIPs was smooth. Worm-like channels or hexagonal tunnels could be observed in the TEM images of mesoporous structure of MIPs. The mesoporous structure also can be further confirmed by nitrogen adsorption-desorption isotherms. Mesoporous structure MIPs display the typical type-IV curves and the actual pore size distribution is given by the Barrett-Joyner-Halenda (BJH) curve.

Mesoporous MIPs are widely used for removal or enrichment of targets due to the high surface area. For example, mesoporous IIPs were prepared for rapid and specific adsorption of $\mathrm{Cr}$ (III) ions in effluents. Due to the mesoporous structure, the adsorption reached equilibrium within $5 \mathrm{~min} .{ }^{196}$ Mesoporous MIPs were prepared for SPE of chloramphenicol from milk.

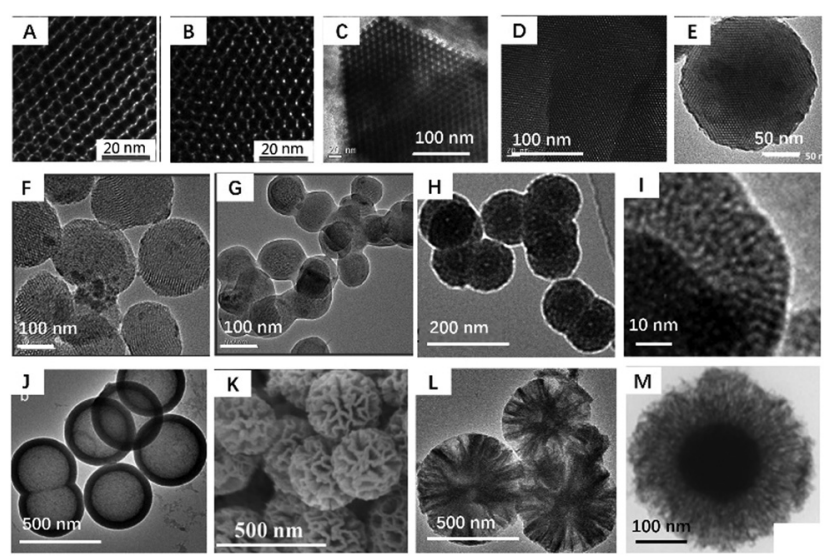

Fig. 9 TEM and SEM images of mesoporous MIPS. TEM images of SBA before (A) and after (B) anchoring of MIP layer, adapted from ref. 193, Copyright 2014. SBA-15 (C) and MCM-41 (D) based Ni(॥) ion imprinted polymers by one-pot synthesis method, adapted from ref. 201, Copyright 2018, Elsevier. (E) Phosphate-imprinted mesoporous silica using dualtemplate method, adapted from ref. 204, Copyright 2015. (F and G) TEM images of magnetic mesoporous silica-based mesoporous core-solid shell MIPs, adapted from ref. 215, Copyright 2016, Elsevier. ( $H$ and I) TEM images of solid core-mesoporous shell MIPs, adapted from ref. 222, Copyright 2015. (J) TEM image of hollow mesoporous MIPS, adapted from ref. 227 Copyright 2017, Elsevier. ( $K$ and L) SEM and TEM images of multilevel mesoporous silica, adapted from ref. 230, Copyright 2019. (M) TEM image of $\mathrm{Fe}_{3} \mathrm{O}_{4}$ afibrous $\mathrm{SiO}_{2}$ after anchoring of MIP layer, adapted from ref. 233, Copyright 2015, American Chemical Society.
The maximum imprinting factor was 9.7, whereas the highest capacity was $23 \mathrm{mg} \mathrm{g}^{-1} \cdot{ }^{197} \mathrm{Ni}$ ion imprinted mesoporous IIPs were employed for removal of $\mathrm{Ni}$ ions from wastewaters with adsorption efficiency above $92.5 \%$ even after seven extraction-stripping cycles. $^{201}$

For the mesoporous structured MIPs prepared by the above method, it cannot be guaranteed that all the recognition sites are located on the surface of the mesoporous MIPs. Most recognition sites are still located in the MIPs. Therefore, it is highly desirable to develop straightforward and efficient imprinting strategies to generate recognition sites on the surface of mesoporous silica. A dual-template (molecular imprinting template and mesoporous template) docking oriented molecular imprinting method for one-pot synthesis of mesoporous MIPs with recognition sites located on the surface of mesoporous silica was proposed..$^{202-206}$ As shown in Fig. 8C, rod-like positively charged CTAB micelles were mixed with negatively charged template to form dualtemplate complexes based on electrostatic attraction. Then an appropriate $\mathrm{Si}$ source precursor co-condensation occurred around the dual-template complexes. After removal of the soft template, recognition sites were located on the surface of mesoporous silica materials. This method was easy to control. Fig. 9E shows a TEM image of phosphate-imprinted mesoporous silica using the dual-template method, with mesopore diameter of $2.6 \mathrm{~nm}$ and specific surface area of $792 \mathrm{~m}^{2} \mathrm{~g}^{-1} \cdot{ }^{204}$ Similarly, $\mathrm{Hu}^{205}$ prepared mesoporous MIPs to recognize phosphorylated tyrosine residue using this dual-template docking method. Template phenylphosphonic acid is negatively charged in alkaline solution, which can be docked onto CTAB micelles to form a dual-template due to electrostatic attraction. However, this imprinting strategy was designed only for charged targets.

The pore size of mesoporous silica using CTAB as the soft template is less than the mean size of proteins, which is not suitable for protein imprinting. Therefore, suitable soft templates, which can generate suitable sizes of mesopores and channels for the diffusion of proteins, are in high demand. Researchers have found that amphiphilic ionic liquids (ILs) consisting of an imidazolium cation and a hydrophobic long alkyl chain along with a kosmotropic anion could be used as soft templates to produce well-ordered mesoporous materials. More importantly, the mesopore size can be tuned by varying the length of the alkyl chain and the anion. So, using the amphiphilic IL 1-octadecyl-3-methylimidazolium chloride (C18MIMCl) as surfactant, Qian ${ }^{206}$ prepared mesoporous MIPs for protein recognition. The imidazolium cation of the IL provided multiple interactions with nonapeptide template, so nonapeptide template was anchored on the surface of C18MIMCl micelle rods to generate surfactant-template complexes. MIPs displayed a fibrous porous morphology that was directed by $\mathrm{C} 18 \mathrm{MIMCl}$. The diameter of spherical MIPs was about $200 \mathrm{~nm}$ and the pore diameter was $3.62 \mathrm{~nm}$. The dimensions of cytochrome $c$ are about $2.6 \mathrm{~nm} \times 3.2 \mathrm{~nm} \times$ $3.3 \mathrm{~nm}$, so the size of the pores produced by ILs is suitable for Cyc imprinting. 
5.1.3 Sponge mesoporous MIPs. In addition to 2D-channel mesoporous silica (MCM-41 and SBA-15), 3D-channel mesoporous silica with highly interconnected 3D pore structures, like cage type SBA-16 or sponge mesoporous silica, has been shown to be superior to $2 \mathrm{D}$ mesoporous silica in mass transfer. For example, Chen ${ }^{207}$ prepared BPA-imprinted sponge mesoporous silica by a semi-covalent imprinting strategy. Sponge mesoporous silica was fabricated through a self-assembly process between lecithin/dodecylamine mixed-micelles and TEOS in an ethanolic/aqueous medium. The specific surface area of sponge mesoporous MIPs was $850.55 \mathrm{~m}^{2} \mathrm{~g}^{-1}$, and the specific adsorption capacity for BPA was $169.22 \mathrm{mmol} \mathrm{g}^{-1}$. The adsorption could reach equilibrium within $3 \mathrm{~min}$. Those excellent properties may be ascribed to highly interconnected 3D porous network. High specific surface area and large pore volume make sponge mesoporous silica suitable for molecular imprinting. However, compared with the wide application range in the fields of controlled drug release and catalysis, 3D mesoporous silicon is less used in MIPs.

5.1.4 Mesoporous MIP doping NPs. Mesoporous structured MIPs have been applied as solid-phase extraction sorbents and for construction of chemical sensors because of their remarkable effect on reducing mass transfer resistance and increasing adsorption capacity. When doping fluorescent nanoparticles (FNPs) during a one-pot synthesis process, fluorescent mesoporous MIPs were prepared. For example, Liang ${ }^{199}$ prepared mesoporous fluorescent MIPs for sensing sparfloxacin in biological samples by doping Mn-doped ZnS QD in the one-pot synthesis system. When doping two kinds of FNPs, ratiometric fluorescent MIPs, ${ }^{208}$ dual reference ratiometric fluorescent MIPs, ${ }^{200}$ or dual channel fluorescent MIPs $^{201}$ can be designed. Chen ${ }^{209}$ proposed a method to prepare fluorescent mesoporous MIPs by anchoring QDs onto the mesoporous MIPs. The preparation of QD@mesoporous MIPs involves the following three steps: the synthesis of mesoporous MIPs, the formation of the QDs, and the combination of these two materials by $\mathrm{KH}-570$ to obtain the final product. However, this method is more complicated than the one-pot method. Furthermore, the bonded QDs are located on the surface of MIPs, so it is difficult to ensure that the QDS are evenly distributed near the recognition sites, which reduces the efficiency from molecular recognition to signal output. Furthermore, exposed QDs can contact with a variety of substances, resulting in reduced detection selectivity. Bonding MNPs in mesoporous silica is a good way to prepare magnetic mesoporous MIPs. For example, $\mathrm{Zhang}^{210}$ grew MNPs in situ in the pores of mesoporous MIPs to prepare magnetic mesoporous MIPs. The as-prepared magnetic mesoporous MIPs displayed the advantage of MNPs of simple separation and the advantage of mesoporous material of faster mass transfer and higher adsorption capacity.

\subsection{Core-shell mesoporous MIPs}

5.2.1 Mesoporous core-solid shell MIPs. Core-shell structured mesoporous MIPs can be divided into two groups: mesoporous core with solid shell and solid core with mesoporous shell. For the mesoporous core with solid shell, recognition sites only exist in the solid shell, the mesoporous core being used as supporting matrix for surface imprinting, as discussed in Section 3. Generally, mesoporous silica nanospheres like BSA$15^{211-214}$ and FDU-12 $2^{98}$ are prepared, followed by surface modification to introduce vinyl double bond by KH-570. Finally MIP layer is coated on the surface of mesoporous silica. For example, Liu coated photo-responsive MIPs using azobenzene-containing monomer as the photosensitive monomer on the surface of mesoporous silica for photo-regulated selective separation of BPA. ${ }^{211}$ It was reported that mesoporous silica was an excellent matrix material that possesses large surface area, highly ordered pore structures and high hydrothermal stability, which can enhance significantly the adsorption capability of adsorbents. $\mathrm{YaO}^{212}$ prepared SBA-15 using triblock-copolymer Pluronic P123 $\left(\mathrm{EO}_{20} \mathrm{PO}_{70} \mathrm{EO}_{20}\right)$ as the surfactant, then modified SBA-15 with MAPS. Then SBA-15@MIPs was prepared by surface imprinting. For comparison, MIPs@SiO ${ }_{2}$ was also prepared. The binding capacity of MIP@SBA-15 (68.29 $\left.\mathrm{mg} \mathrm{g}^{-1}\right)$ was about 1.67 -fold that

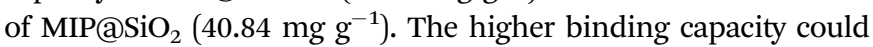
be due to the higher surface area of SBA-15.

These kinds of mesoporous core-solid shell MIPs are often used for selective extraction and enrichment of targets from complicated sample matrices. However, separation of those mesoporous core-shell MIPs is difficult because of the small particle size. So Yan $^{215}$ prepared core-shell magnetic mesoporous MIPs for specific magnetic separation of BPA. The novelty of this work was using magnetic mesoporous silica as supporting matrix. Mesoporous silica was first prepared, followed by embedding of MNPs into the pores of mesoporous silica. The as-prepared MIPs combined the advantages of magnetic separation and faster mass transfer and higher adsorption capacity stemming from the mesoporous support. Fig. 9F and G display the TEM images of magnetic mesoporous silica and the core-shell MIPs. An imprinted MIP layer coated on the magnetic mesoporous silica could be observed clearly. Magnetic mesoporous silica also can be prepared by pyrolysis method. For example, Liu ${ }^{216}$ prepared magnetic mesoporous MIPs for $\mathrm{Sr}(\mathrm{II})$ by RAFT polymerization. First, $\mathrm{Fe}_{3} \mathrm{O}_{4}$ @SBA-15 was obtained by calcining SBA-15 and $\mathrm{Fe}\left(\mathrm{NO}_{3}\right)_{3}$ in $\mathrm{N}_{2}$ flowing atmosphere. Then $\mathrm{Fe}_{3} \mathrm{O}_{4} @ S B A-15$ was modified with APTES and RAFT agent. The imprinted polymers were obtained on the external and internal surfaces of $\mathrm{Fe}_{3} \mathrm{O}_{4} @ S B A-15$ through RAFT polymerization.

Many scholars have pointed out that binding capacity is increased by using a mesoporous core. However, we think the effect of mesoporous cores on the binding capacity is not obvious. This is because the surface of a mesoporous core is covered with solid imprinted shell, and the effective recognition sites are only located within a dozen nanometers of the MIP surface. Unless ultra-thin imprinted shell of several nanometers is covered on the surface of the mesoporous core, the advantages of the mesoporous core cannot be realized. From the viewpoint of increasing adsorption capacity, it is more effective to prepare MIPs with mesoporous shells.

5.2.2 Solid core and mesoporous shell MIPs. The second type of core-shell mesoporous MIPs has a solid core and 
mesoporous shell, in which recognition sites are located in the mesoporous shell. The cores endow the MIPs with special properties, such as magnetic separation and fluorescence properties. Adsorption capacity can be significantly improved via the mesoporous shell. Therefore, the solid core-mesoporous shell MIPs are widely applied for construction of chemical sensors or target enrichment. Generally $\mathrm{Fe}_{3} \mathrm{O}_{4}{ }^{217,218}$ and $\mathrm{SiO}_{2}{ }^{219-225}$ are employed as the solid core and the mesoporous shell layer is formed during the molecular imprinting process. The preparation process is similar to that of core-shell MIPs. Solid $\mathrm{SiO}_{2}$ core-mesoporous shell MIPs are usually used to construct fluorescent sensors. The usual method is to coat a mesoporous imprinted layer on the surface of $\mathrm{SiO}_{2}$ microspheres by the sol-gel method, in which FNPs were doped in the mesoporous imprinting layer. In this kind of fluorescent sensor, the FNPs are randomly distributed in the imprinted layer, and sometimes aggregated in the polymers. In order to make the fluorescent nanoparticles evenly distributed in the shell, FNPs are anchored on the surface of $\mathrm{SiO}_{2}$ nanoparticles, and then the mesoporous shell is deposited to fabricate core-shell mesoporous MIPs. Using this method, several core-shell mesoporous MIP fluorescent sensors were designed for detection of phycocyanin, ${ }^{219}$ transferrin, ${ }^{220}$ 2,4-dichlorophenoxyacetic acid, ${ }^{221}$ etc. The above discussed mesoporous fluorescent MIP sensors are single-emission sensors, visual detection being hard to achieve. A ratiometric fluorescent sensor, which usually contains two FNPs, can improve the detection sensitivity and achieve visual detection based on the fluorescence color change of two fluorescent dyes. Our group ${ }^{222}$ pioneered a ratiometric MIP fluorescent sensor for TNT detection. In this strategy, red CdTe QDs as reference dye were embedded in silica as the core, and mesoporous MIP layer was coated onto the surface of silica using green CdTe QD as a TNT-sensitive FNP via a sol-gel procedure. Before rebinding TNT, yellow-green fluorescence stemming from green QDs and red QDs was observed. The green QDs were quenched by the rebound TNT while the red QD fluorescence kept constant with the protection of the silica shell. Hence, the fluorescence color changed from yellow-green to red-orange obviously, facilitating the visual detection of TNT. TEM images of QDs@ $\mathrm{SiO}_{2}$ and solid core-mesoporous shell MIPs confirmed the successful synthesis of core-shell MIPs, as displayed in Fig. 9H and I. The worm-like channels indicated the mesoporous channels. Inspired by the pioneering work, core-mesoporous shell structured ratiometric fluorescent MIPs were prepared for determination of malachite green, ${ }^{223}$ 2,4,6-trinitrophenol, ${ }^{224}$ diniconazole, ${ }^{225}$ etc.

Solid $\mathrm{Fe}_{3} \mathrm{O}_{4}$ core-mesoporous shell MIPs are usually used for extraction of target from complicated samples. Magnetic mesoporous yolk-shell MIPs also were prepared for extraction of $17 \beta$-estradiol (E2). ${ }^{226}$ First, $\mathrm{Fe}_{3} \mathrm{O}_{4}$ was coated with an inorganic $\mathrm{SiO}_{2}$ layer. Then mesoporous MIP layer was coated on the surface of $\mathrm{Fe}_{3} \mathrm{O}_{4} @ \mathrm{SiO}_{2}$ using APTES as functional monomer, bis(triethoxysilyl)benzene (BTESE) as organic crosslinker, and $\mathrm{CTAB}$ as soft template for mesopores. To form the magnetic mesoporous yolk-shell structure, the inorganic $\mathrm{SiO}_{2}$ was etched by $\mathrm{NaCO}_{3}$ solution. The magnetic mesoporous yolk-shell structure
MIPs were applied to magnetic solid-phase extraction (MSPE) of E2. Recoveries ranged from 88.3 to $102.4 \%$ and the relative standard deviations (RSDs) were lower than 5.5\%.

\subsection{Hollow mesoporous MIPs}

Hollow mesoporous MIPs (HM-MIPs) can be prepared by etching of the core as discussed in Section 4. First, solid core-mesoporous shell structure MIPs are prepared, and then the cores are etched to form hollow mesoporous MIPs. For example, in our previous work, ${ }^{226}$ HM-MIPs were prepared by a one-pot surface imprinting method followed by chemical selective etching to remove the solid silica core. First, solid $\mathrm{SiO}_{2}$ was synthesized using inorganic TEOS as precursor. Then mesoporous E2-imprinted layer was coated onto the surface of inorganic $\mathrm{SiO}_{2}$ using organosilica precursor bis(triethoxysilyl)benzene instead of TEOS. Solid inorganic $\mathrm{SiO}_{2}$ was etched by hot $\mathrm{Na}_{2} \mathrm{CO}_{3}$ solution to form hollow voids. It should be pointed out that the organosilica is much more stable than inorganic silica, so the organosilica mesoporous shell could be well preserved after etching. Fig. 9J shows the E2-imprinted hollow mesoporous MIPs. The diameter of HM-MIPs was about $460 \mathrm{~nm}$ while the thickness of the shell was about $55 \mathrm{~nm}$. HMMIPs displayed a higher binding capacity $\left(18.3 \mathrm{mg} \mathrm{g}^{-1}\right)$ when compared with hollow MIPs (12.15 $\left.\mathrm{mg} \mathrm{g}^{-1}\right)^{227}$ and core-shell mesoporous MIPs (2.93 $\left.\mathrm{mg} \mathrm{g}^{-1}\right) .{ }^{125}$

HM-MIPs also can be prepared by grafting MIPs onto hollow mesoporous silica. For example, $\mathrm{Li}^{228}$ prepared $\mathrm{Pb}$ (II) ion imprinted hollow mesoporous MIPs by imprinting on the surface of hollow mesoporous silica. The hollow mesoporous silica was prepared by etching $\mathrm{SiO}_{2} @ \mathrm{mSiO}_{2}$ by $\mathrm{Na}_{2} \mathrm{CO}_{3}$ solution. Then a suspension polymerization procedure was adopted for the preparation of HM-MIPs. Using hollow mesoporous silica as solid matrix, Li also prepared HM-MIPs for extraction of trace BPA in real water samples. ${ }^{229}$ Comparing the above two methods, the first method involved in the one pot preparation of core-mesoporous shell MIPs and then etching of the core layer was simpler.

\subsection{Multilevel mesoporous MIPs}

Multilevel mesoporous silica has many kinds of channels with different sizes, from mesoporous channels to macropores. MIPs employing multilevel mesoporous silica combine the advantages of mesoporous and macroporous structures. The coexistence of multiple-scale pores may enhance and harmonize the diffusion of guest molecules. For example, in our previous work, ${ }^{230}$ BPA-imprinted multilevel mesoporous silica was prepared. During the preparation process, water, ethanol and ethyl ether were employed as co-solvents. CTAB micelles were employed to form mesopores, while the heterogeneous gasification of ethyl ether formed large mesopores. Fig. 9K and $\mathrm{J}$ show SEM and TEM images of multilevel mesoporous silica, shaped like a hydrangea flower. These multilevel mesoporous MIPs were employed to produce a fluorescent sensor by postimprinting strategy by anchoring FNPs on the large mesopores. The small mesopores led to increased surface area, and facilitated the diffusion of BPA. The advantage of multilevel mesoporous silica is that QDs can be uniformly bonded in MIPs due 
to the presence of large pores, and the bound QDs do not hinder the adsorption of BPA. The sensitivity of the p-MIFPs was two orders of magnitude higher than that of the d-MIFPs.

$\mathrm{Liu}^{231}$ prepared Ni(II)-IIP by surface imprinting on microporous-mesoporous silica. P123 was used as soft template to form mesopores while solid PS particles were used to form macropores. After modification with MPA, Ni(II) imprinting was carried out using $\mathrm{AM}$ as functional monomer and EGDMA as crosslinker. The results proved that the introduction of macropores facilitated mass transfer and reduced transport limitations.

The pore size of mesoporous silica using CTAB as a soft template was less than $3 \mathrm{~nm}$, which was not suitable for protein imprinting. Fibrous silica was synthesized using a biphase reaction. CTAB and urea were dissolved in $\mathrm{H}_{2} \mathrm{O}$ as the aqueous phase, and a mixture of cyclohexane, isopropanol, and TEOS was the oil phase. The oil phase and water phase were mixed and stirred at a fixed rate. By simply controlling the stirring rate, the pore size can be tuned. The pore size of fibrous silica can be tuned from a few nanometers to tens of nanometers. Multilevel mesoporous silica like fibrous silica also could be used as a solid matrix to prepare MIPs by surface imprinting. ${ }^{232,233}$ For example, Ge's group ${ }^{233}$ prepared lysozyme-imprinted PDA layer on $\mathrm{Fe}_{3} \mathrm{O}_{4} @$ @fibrous $\mathrm{SiO}_{2}$ microspheres. Fibrous $\mathrm{SiO}_{2}$ was coated on the surface of $\mathrm{Fe}_{3} \mathrm{O}_{4}$. The size of fibrous channel was about $12 \mathrm{~nm}$ and the specific surface area of $\mathrm{Fe}_{3} \mathrm{O}_{4}$ @fibrous $\mathrm{SiO}_{2}$ support was $570 \mathrm{~m}^{2} \mathrm{~g}^{-1}$. After lysozyme imprinting, the surface area of MIP-lysozyme was $309 \mathrm{~m}^{2} \mathrm{~g}^{-1}$, and the intensity of the pores with diameter of $12 \mathrm{~nm}$ decreases only 12\%, which indicates PDA only attached to the surface of the pores of $\mathrm{Fe}_{3} \mathrm{O}_{4} @ \mathrm{~F}-\mathrm{SiO}_{2}$, rather than completely blocking those pores. Due to the high surface area of $\mathrm{Fe}_{3} \mathrm{O}_{4}$ @fibrous $\mathrm{SiO}_{2}$ support, the obtained $\mathrm{Fe}_{3} \mathrm{O}_{4} @$ fibrous $\mathrm{SiO}_{2} @ P D A$ microspheres have a high saturation adsorption capacity of lysozyme of $700 \mathrm{mg} \mathrm{g}^{-1}$ within $30 \mathrm{~min}$. Fig. 9M shows a TEM image of lysozyme-imprinted $\mathrm{Fe}_{3} \mathrm{O}_{4} @$ ${\mathrm{F}-S i O_{2} @ P D A}_{2}$ which displays the clear core-shell structure and radial fibers.

\section{Conclusions and outlook}

In the past two decades, great progress has been made in the development of MIPs with different morphologies. Various methods have been developed to generate MIPs with the desired size, shape and particle size distribution. Many kinds of spherical, core-shell, hollow, mesoporous and porous MIPs have been successfully prepared for packed columns, enrichment of targets, and chemical sensors. The diameter and size of MIP particles are affected by the preparation method and morphology. As shown in Fig. 10, we analyzed the size of MIPs from about 200 references listed in this article, and arrived at the following conclusions. The particle size of mesoporous MIPs prepared by one-pot methods is generally below $100 \mathrm{~nm}$ with good dispersivity. The size of core-shell structured MIPs (including solid core-solid shell, solid core-mesoporous shell and mesoporous core-solid shell) is slightly larger, being distributed between $100 \mathrm{~nm}$ and $1000 \mathrm{~nm}$, depending on the size of the core material. The size of hollow MIPs obtained by etching of cores is similar to that of core-shell structures, while the size of hollow MIPs prepared by the seed swelling method is larger, about 3-5 $\mu \mathrm{m}$. The particle size of solid spherical MIPs is greatly affected by the polymerization method. The spherical MIPs prepared by precipitation

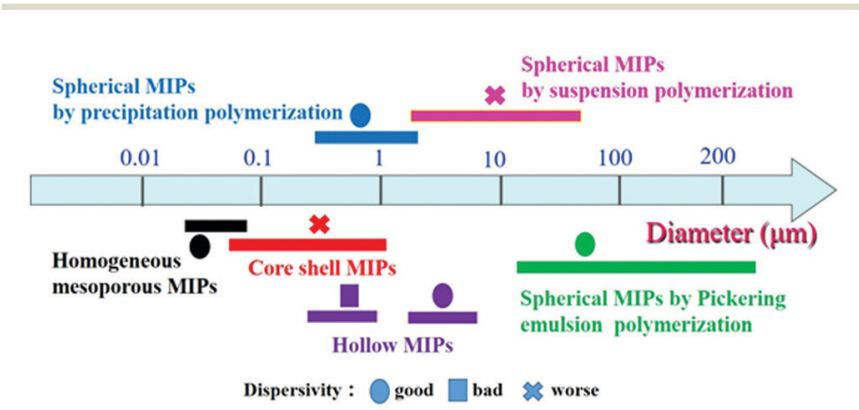

Fig. 10 The diameter distribution of MIPs with different morphologies obtained using different preparation methods.

Table 1 Comparison of different spherical MIPs

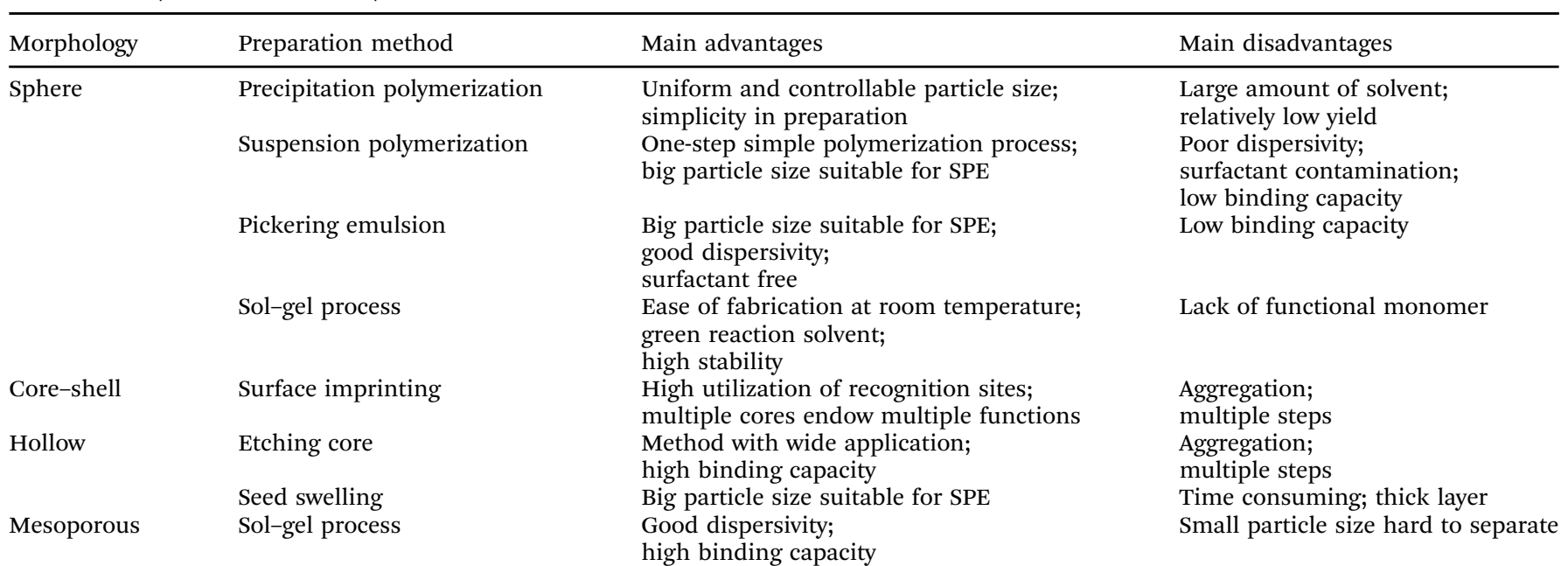


polymerization are mostly in the range of $0.5-5 \mu \mathrm{m}$, while the particle size obtained by Pickering polymerization and suspension polymerization is larger, in the range of tens to hundreds of micrometers.

At the same time, we can choose the appropriate morphology and preparation method for the application field. For example, for SPE adsorbents, Pickering emulsion polymerization and suspension polymerization can be used to prepare large size MIPs. In order to get improved adsorption capacity, hollow or mesoporous MIPs can be selected. If one wants to endow MIPs with performances like photodegradation and magnetic separation, core-shell structured MIPs are a good choice. The spherical MIPs prepared by precipitation polymerization have a wide particle size distribution and can be used in many fields. The main advantages and disadvantages of different morphologies are listed in Table 1.

There is a lot of work that needs to be done in the future to improve the morphology of MIPs.

(i) Many of the existing morphologies are unsatisfactory. For example, although living polymerization has been employed to prepare MIPs, the dispersion of spherical MIPs is not ideal. The phenomena of adhesion and agglomeration are commonly observed for many core-shell MIPs, and the recognition sites are still difficult to use due to the thick shell. Many hollow MIPs collapse easily and fracture, and imprinting in the pores of mesoporous silica is still difficult.

(ii) The kinds of morphology of MIPs are relatively rare, and most of the morphologies are relatively simple. Many new morphologies, such as dumbbell and Janus, have not been used in MIPs. This may be because the ideal application areas of these special structures have not been found.

(iii) Attention for most MIPs has focused on separation/ purification/detection in environmental, food and biological matrices. Fewer MIPs have been employed in vivo and in cells. The good news is that fluorescent MIPs have been employed for drug delivery and cell imaging in cells using a dual-template imprinting strategy. ${ }^{234,235}$ In the future, the application of spherical MIPs can be extended to in vivo and cells.

(iv) Due to the small space of recognition sites, the existing recognition sites in MIPs cannot be characterized. Many imprinting strategies, like solid-phase imprinting and dualtemplate oriented imprinting, cannot be strongly supported by the existing morphology characterization methods.

(v) There are many factors affecting the adsorption capacity of MIPs, such as morphology, particle size, functional monomer, solvent and so on. The adsorption capacity of MIPs and detection sensitivity of MIP-based chemical sensors should be improved by many aspects together.

\section{List of abbreviations and acronyms}

$\begin{array}{ll}\text { AAm } & \text { Acrylamide } \\ \text { APTES } & \text { 3-Aminopropyltriethoxysilane } \\ \text { ATRP } & \text { Atom transfer radical polymerization } \\ \text { AuNCs } & \text { Gold nanoclusters }\end{array}$

AAm Acrylamide

AuNCs Gold nanoclusters

\begin{tabular}{|c|c|}
\hline BET & Brunauer-Emmett-Teller \\
\hline $\mathrm{BHb}$ & Bovine hemoglobin \\
\hline BPA & Bisphenol A \\
\hline BSA & Bovine serum albumin \\
\hline BTESE & Bis(triethoxysilyl)benzene \\
\hline CDs & Carbon dots \\
\hline CTAB & Cetyltrimethylammonium bromide \\
\hline DA & Dopamine \\
\hline DPP & Distillation precipitation polymerization \\
\hline DVB & Divinylbenzene \\
\hline $\mathrm{E} 2$ & $17 \beta$-Estradiol \\
\hline EGDMA & Ethylene glycol dimethacrylate \\
\hline FNPs & Fluorescent nanoparticles \\
\hline GMA & Glycidyl methacrylate \\
\hline HEMA & Hydroxyethyl methacrylate \\
\hline HM-MIPs & Hollow mesoporous MIPs \\
\hline HMS & Hollow mesoporous silica \\
\hline IIPs & Ion imprinted polymers \\
\hline ILs & Ionic liquids \\
\hline IPTS & 3-Isocyanatopropylethoxysilane \\
\hline MAA & Methacrylic acid \\
\hline MAPS & Methacryloxypropyltrimethoxysilane \\
\hline M-H-MIPs & Magnetic hollow MIPs \\
\hline MIPs & Molecularly imprinted polymers \\
\hline M-MIPs & Magnetic MIPs \\
\hline MNPs & Magnetic nanoparticles \\
\hline MOF & Metal-organic framework \\
\hline MSPE & Magnetic solid-phase extraction \\
\hline NIPAm & $N$-Isopropylacrylamide \\
\hline NPs & Nanoparticles \\
\hline OVA & Ovalbumin \\
\hline P123 & $\mathrm{EO}_{20} \mathrm{PO}_{70} \mathrm{EO}_{20}$ \\
\hline PDA & Polydopamine \\
\hline PEG & Polyethylene glycol \\
\hline PHEMA & Polyhydroxyethyl methacrylate \\
\hline PMMA & Poly(methyl methacrylate) \\
\hline PNIPAAm & Poly( $N$-isopropylacrylamide) \\
\hline PS & Polystyrene \\
\hline PVA & Poly(vinyl alcohol) \\
\hline QDs & Quantum dots \\
\hline RAFT & $\begin{array}{l}\text { Reversible addition-fragmentation chain } \\
\text { transfer }\end{array}$ \\
\hline RAM-MIPs & Restricted access material MIPs \\
\hline RPP & Reflux precipitation polymerization \\
\hline SDS & Sodium dodecyl sulfate \\
\hline SEM & Scanning electron microscope \\
\hline SPE & Solid-phase extraction \\
\hline TBBPA & Tetrabromobisphenol A \\
\hline TEM & Transmission electron microscope \\
\hline TEOS & Tetraethoxysilane \\
\hline TRIM & Trimethylolpropane trimethacrylate \\
\hline $2 \mathrm{D}$ & Two dimensional \\
\hline $2,4-\mathrm{D}$ & 2,4-Dichlorophenoxyacetic acid \\
\hline $3 \mathrm{D}$ & Three dimensional \\
\hline $4-\mathrm{VP}$ & 4-Vinylpyridine \\
\hline$\beta$-CDs & $\beta$-Cyclodextrins \\
\hline
\end{tabular}




\section{Conflicts of interest}

There are no conflicts to declare.

\section{Acknowledgements}

This work was supported by the National Natural Science Foundation of China (21777065) and Youth Innovation Project for Colleges of Shandong Province (2019KJA021).

\section{Notes and references}

1 L. Chen, S. Xu and J. Li, Chem. Soc. Rev., 2011, 40, 2922-2942.

2 L. Chen, X. Wang, W. Lu, X. Wu and J. Li, Chem. Soc. Rev., 2016, 45, 2137-2211.

3 C. Alexander, H. S. Andersson, L. I. Andersson, R. J. Ansell, N. Kirsch, I. A. Nicholls, J. O'Mahony and M. J. Whitcombe, J. Mol. Recognit., 2006, 19, 106-180.

4 16W. Cheng, X. Zeng, H. Chen, Z. Li, W. Zeng, L. Mei and Y. Zhao, ACS Nano, 2019, 13, 8537-8565.

5 T. Zhou, L. Ding, G. Che, W. Jiang and L. Sang, TrAC, Trends Anal. Chem., 2019, 114, 11-28.

6 S. Xu, H. Lu, X. Zheng and L. Chen, J. Mater. Chem. C, 2013, 1, 4406-4422.

7 J. Fu, L. Chen, J. Li and Z. Zhang, J. Mater. Chem. A, 2015, 3, 13598-13627.

8 Q. Yang, J. Li, X. Wang, H. Peng, H. Xiong and L. Chen, Biosens. Bioelectron., 2018, 112, 54-71.

9 M. Sobiech, P. Bujak, P. Luliński and A. Pron, Nanoscale, 2019, 11, 12030-12074.

10 X. Guo, J. Li, M. Arabi, X. Wang, Y. Wang and L. Chen, ACS Sens., 2020, 5, 601-619.

11 P. Wang, X. Sun, X. Su and T. Wang, Analyst, 2016, 141, 3540-3553.

12 S. Farooq, J. Nie, Y. Cheng, Z. Yan and J. Li, Analyst, 2018, 143, 3971-3989.

13 R. Gui, H. Guo and H. Jin, Nanoscale Adv., 2019, 1, 3325-3363.

14 J. Pan, W. Chen, Y. Ma and G. Pan, Chem. Soc. Rev., 2018, 47, 5574-5587.

15 R. Xing, Y. Wen, H. He, Z. Guo and Z. Liu, TrAC, Trends Anal. Chem., 2019, 110, 417-428.

16 R. Schirhagl, Anal. Chem., 2014, 86, 250-261.

17 G. Sharma and B. Kandasubramanian, J. Chem. Eng. Data, 2020, 65, 396-418.

18 V. Pichon, N. Delaunay and A. Combès, Anal. Chem., 2020, 92, 16-33.

19 L. Wan, Z. Chen, C. Huang and X. Shen, TrAC, Trends Anal. Chem., 2017, 95, 110-121.

20 J. E. Lofgreen and G. A. Ozin, Chem. Soc. Rev., 2014, 43, 911-933.

21 M. Dinc, C. Esen and B. Mizaikoff, TrAC, Trends Anal. Chem., 2019, 114, 202-217.

22 T. Alizadeh and N. Memarbashi, Sep. Purif. Technol., 2012, 90, 83-91.
23 C. Gonzato, P. Pasetto, F. Bedoui, P. Mazeranc and K. Haupt, Polym. Chem., 2014, 5, 1313-1322.

24 M. R. Halhalli and B. Sellergren, Polym. Chem., 2015, 6, 7320-7332.

25 D. Wang, S. Hong, G. Yang and K. Row, Korean J. Chem. Eng., 2003, 20, 1073-1076.

26 J. Sun, J. Dai, W. Ma, L. Gao, A. Xie, J. He, X. Wei, Z. Zhou, C. Li and Y. Yan, J. Iran. Chem. Soc., 2016, 13, 489-497.

27 Y. Lu, Y. Zhu, Y. Zhang and K. Wang, J. Chem. Eng. Data, 2019, 64, 1045-1050.

28 J. Haginaka, C. Miura, N. Funaya and H. Matsunaga, Anal. Sci., 2012, 28, 315-317.

29 C. Miura, H. Li, H. Matsunaga and J. Haginaka, J. Pharm. Biomed. Anal., 2015, 114, 139-144.

30 S. Xu, J. Li and L. Chen, Talanta, 2011, 85, 282-289.

31 T. Zhou, L. Jørgensen, M. Mattebjerg, I. Chronakis and L. Ye, RSC Adv., 2014, 4, 30292-30299.

32 R. Song, X. Hu, P. Guan, J. Li, L. Qian and Q. Wang, Chin. J. Polym. Sci., 2015, 33, 404-415.

33 W. Han, L. Gao, X. Li, L. Wang, Y. Yan, G. Chen, B. Hu, X. Lin and M. Song, RSC Adv., 2016, 6, 81346-81353.

34 M. J. Garcia-Soto, K. Haupt and C. Gonzato, Polym. Chem., 2017, 8, 4830-4834.

35 F. Bai, X. Yang and W. Huang, Macromolecules, 2004, 37, 9746-9752.

36 K. Yang, M. M. Berg, C. Zhao and L. Ye, Macromolecules, 2009, 42, 8739-8746.

37 Y. Liu, L. Zhang, N. Zhao, Y. Han, F. Zhao, Z. Penge and Y. Li, Analyst, 2017, 142, 1091-1098.

38 M. Safdarian and Z. Ramezani, New J. Chem., 2019, 43, 48-57.

39 X. Shen, C. Huang, S. Shinde, M. SwitnickaPlak, P. Cormack and B. Sellergren, RSC Adv., 2016, 6, 81491-81499.

40 P. Lenain, J. D. D. Mavungu, P. Dubruel, J. Robbens and S. Saeger, Anal. Chem., 2012, 84, 10411-10418.

41 N. Shah, J. H. Ha, M. Ul-Islam and J. K. Park, Korean J. Chem. Eng., 2011, 28, 1936-1944.

42 X. Shen and L. Ye, Chem. Commun., 2011, 47, 10359-10361.

43 X. Shen, C. Xu and L. Ye, Soft Matter, 2012, 8, 7169-7176.

44 T. Fan, W. Yang, N. Wang, X. Ni, J. Wen and W. Xu, J. Appl. Polym. Sci., 2016, 133, 43484.

45 M. Kujawska, T. Zhou, A. W. Trochimczuk and L. Ye, J. Mol. Recognit., 2017, e2626.

46 J. Li, X. Hu, P. Guan, X. Zhang, L. Qian, N. Zhang, C. Du and R. Song, J. Sep. Sci., 2016, 39, 1863-1872.

47 H. Sun, Y. Li, J. Yang, X. Sun, C. Huang, X. Zhang and J. Chen, J. Sep. Sci., 2016, 39, 2188-2195.

48 T. Zhou, X. Shen, S. Chaudhary and L. Ye, J. Appl. Polym. Sci., 2014, 131, 39606.

49 X. Shen and L. Ye, Macromolecules, 2011, 44, 5631-5637.

50 C. Passini, L. Anfossi, F. Nardo, G. Spano, V. Maurino and C. Baggiani, J. Sep. Sci., 2015, 38, 3661-3668.

51 Z. Wang, T. Qiu, L. Guo, J. Ye, L. He and X. Li, Chem. Eng. J., 2018, 332, 409-418.

52 M. G. Ayari, P. Kadhirvel, P. Favetta, B. Plano, C. Dejous, B. Carbonnier and L. A. Agrofoglio, Mater. Sci. Eng., C, 2019, 101, 254-263. 
53 X. Shen, T. Zhou and L. Ye, Chem. Commun., 2012, 48, 8198-8200.

54 J. Pan, W. Zhu, X. Dai, X. Yan, M. Gan, L. Li, H. Hang and Y. Yan, RSC Adv., 2014, 4, 4435-4443.

55 Y. Sun, J. Chen, Y. Li, H. Li, X. Zhu, Y. Hu, S. Huang, J. Li and S. Zhong, New J. Chem., 2016, 40, 8745-8752.

56 H. Hang, C. Li, J. Pan, L. Li, J. Dai, X. Dai, P. Yu and Y. Feng, J. Sep. Sci., 2013, 36, 3285-3294.

57 Y. Zhu, D. Jiang, D. Sun, Y. Yan and C. Li, J. Environ. Chem. Eng., 2016, 4, 3570-3579.

58 J. Pan, L. Li, H. Hang, R. Wu, X. Dai, W. Shi and Y. Yan, Langmuir, 2013, 29, 8170-8178.

59 W. Zhu, W. Ma, C. Li, J. Pan and X. Dai, Chem. Eng. J., 2015, 276, 249-260.

60 R. Jalilian, M. Shahmari, A. Taheria and K. Gholami, Ultrason. Sonochem., 2020, 61, 104802.

61 H. Ou, Q. Chen, J. Pan, Y. Zhang, Y. Huang and X. Qi, J. Hazard. Mater., 2015, 289, 28-37.

62 X. Shen, J. S. Bonde, T. Kamra, L. Bülow, J. C. Leo, D. Linke and L. Ye, Angew. Chem., Int. Ed., 2014, 53, 10687-10690.

63 H. Li, H. Zhou, H. Wang, P. Yang and S. Zhong, J. Sep. Sci., 2015, 38, 1365-1371.

64 Y. Sun, T. Ren, Z. Deng, Y. Yang and S. Zhong, New J. Chem., 2018, 42, 7355-7363.

65 Y. Sun, Y. Li, J. Xu, L. Huang, T. Qiu and S. Zhong, Colloids Surf., B, 2017, 155, 142-149.

66 Y. Sun and S. Zhong, Colloids Surf., B, 2017, 159, 131-138.

67 W. Zhu, W. Ma, C. Li, J. Pan, X. Dai, M. Gan, Q. Qu and Y. Zhang, Eng. Aspects, 2014, 453, 27-36.

68 R. Yin, L. Chen and L. Ma, J. Sep. Sci., 2019, 42, 3563-3570.

69 C. Liu, Z. Song, J. Pan, X. Wei, L. Gao, Y. Yan, L. Li, J. Wang, R. Chen, J. Dai and P. Yu, J. Phys. Chem. C, 2013, 117, 10445-10453.

70 G. Pan, Y. Ma, Y. Zhang, X. Guo, C. Li and H. Zhang, Soft Matter, 2011, 7, 8428-8439.

71 Y. Ma, Y. Zhang, M. Zhao, X. Guo and H. Zhang, Chem. Commun., 2012, 48, 6217-6219.

72 J. Jiang, Y. Zhang, X. Guo and H. Zhang, RSC Adv., 2012, 2, 5651-5662.

73 M. Zhao, X. Chen, H. Zhang, H. Yan and H. Zhang, Biomacromolecules, 2014, 15, 1663-1675.

74 M. Zhao, C. Zhang, Y. Zhang, X. Guo, H. Yan and H. Zhang, Chem. Commun., 2014, 50, 2208-2210.

75 C. Li, Y. Ma, H. Niu and H. Zhang, ACS Appl. Mater. Interfaces, 2015, 7, 27340-27350.

76 H. Niu, Y. Yang and H. Zhang, Biosens. Bioelectron., 2015, 74, 440-446.

77 Y. Yang, H. Niu and H. Zhang, ACS Appl. Mater. Interfaces, 2016, 8, 15741-15749.

78 Y. Yang, Z. Wang, H. Niu and H. Zhang, Biosens. Bioelectron., 2016, 86, 580-587.

79 Y. Ma, Ji. Gao, C. Zheng and H. Zhang, J. Mater. Chem. B, 2019, 7, 2474-2483.

80 S. Xu, H. Lu and L. Chen, J. Chromatogr. A, 2014, 1350, 23-29.
81 F. Lin, J. Chen, M. Lee, B. Li and J. Wang, ACS Appl. Nano Mater., 2020, 3, 1147-1152.

82 S. H. Yang, H. Fan, R. J. Classon and K. A. Schug, J. Sep. Sci., 2013, 36, 2922-2938.

83 T. Liang, L. Chen and Y. Ma, J. Chromatogr. A, 2020, 1609, 460453.

84 Z. Sun, H. Liu, Y. Zhou, S. Zhao, J. Li, X. Wang and B. Gong, RSC Adv., 2019, 9, 27953-27960.

85 H. Liu, J. Ding, K. Zhang and L. Ding, Talanta, 2020, 209, 120508.

86 F. Puoci, F. Iemma, G. Cirillo, M. Curcio, O. I. Parisi, U. G. Spizzirri and N. Picci, Eur. Poly. J., 2009, 45, 1634-1640.

87 J. He, L. Song, S. Chen, Y. Li, H. Wei, D. Zhao, K. Gu and S. Zhang, Food Chem., 2015, 187, 331-337.

88 Y. Zhou, H. Liu, J. Li, Z. Sun, T. Cai, X. Wang, S. Zhao and B. Gong, J. Chromatogr. A, 2020, 1613, 460684.

89 F. A. C. Suquila, L. L. G. de Oliveira and C. R. T. Tarley, Chem. Eng. J., 2018, 350, 714-728.

90 Z. Sun, H. Liu, Y. Zhou, S. Zhao, J. Li, X. Wang and B. Gong, RSC Adv., 2019, 9, 27953-27960.

91 L. L. G. de Oliveira, F. A. C. Suquilaa, F. M. de Oliveiraa, G. L. Scheela and C. R. T. Tarley, React. Funct. Polym., 2019, 134, 93-103.

92 D. Wang, D. Gao, Y. Huang, W. Xu and Z. Xia, Talanta, 2019, 202, 392-401.

93 K. Chin and S. Chang, ACS Appl. Nano Mater., 2019, 2, 89-99.

94 R. Fernandes, M. Dinc, I. Raimundo Jr. and B. Mizaikoff, Microporous Mesoporous Mater., 2018, 264, 28-34.

95 X. Yang, Y. Sun, Y. Xiang, F. Qiu and G. Fu, Analyst, 2019, 144, 5439-5448.

96 Q. Li, K. Yang, Y. Liang, B. Jiang, J. Liu, L. Zhang, Z. Liang and Y. Zhang, ACS Appl. Mater. Interfaces, 2014, 6, 21954-21960.

97 M. R. Halhalli, C. S. A. Aureliano, E. Schillinger, C. Sulitzky, M. M. Titirici and B. Sellergren, Polym. Chem., 2012, 3, 1033-1042.

98 C. Rui, J. He, Y. Li, Y. Liang, L. You, L. He, K. Li and S. Zhang, Talanta, 2019, 201, 342-349.

99 J. Guo, H. Chen and X. Wei, J. Chem. Eng. Data, 2019, 64, 4005-4012.

100 H. Wang, Y. Liu, S. Yao and P. Zhu, Food Chem., 2018, 240, 1262-1267.

101 D. Rahangdale and A. Kumar, Carbohydr. Polym., 2018, 202, 334-344.

102 Z. Iskierko, P. Sharma, D. Prochowicz, K. Fronc, F. D’Souza, D. Toczydłowska, F. Stefaniak and K. Noworyta, ACS Appl. Mater. Interfaces, 2016, 8, 19860-19865.

103 K. Qian, G. Fang and S. Wang, Chem. Commun., 2011, 47, 10118-10120.

104 Z. Sun, H. Liu, Y. Zhou, Sh. Zhao, J. Li, X. Wang and B. Gong, RSC Adv., 2019, 9, 27953-27960.

105 Z. Wei, R. Zhang, L. Mu, Y. Huang and Z. Liu, Eur. Polym. J., 2019, 121, 109301.

106 H. Liu, L. Mu, Xi. Chen, J. Wang, S. Wang and B. Sun, J. Agric. Food Chem., 2017, 65, 986-992. 
107 Y. Huang and R. Wang, J. Mater. Chem. A, 2019, 7, 12105-12114.

108 C. Fan, J. Liu, H. Zhao, L. Li, M. Liu, J. Gao and L. Ma, RSC Adv., 2019, 9, 33678-33683.

109 T. S. Anirudhan and S. MadananAnju, J. Environ. Chem. Eng., 2019, 7, 103355.

110 R. Fiorenza, A. Di Mauro, M. Cantarella, A. Gulino, L. Spitaleri, V. Privitera and G. Impellizzeri, Mater. Sci. Semicond. Process., 2020, 112, 105019.

111 H. Basan, M. Dinca and B. Mizaikoff, Anal. Methods, 2018, 10, 997-1005.

112 Q. Liu, J. Wan and X. Cao, Process Biochem., 2018, 70, 168-178.

113 X. Wang, J. Yu, J. Li, Q. Kang, D. Shen and L. Chen, Sens. Actuators, B, 2018, 255, 268-274.

114 W. Zhang, W. Liu, P. Li, H. Xiao, H. Wang and B. Tang, Angew. Chem., 2014, 126, 12697-12701.

115 X. Wu, Z. Zhan, J. Li, H. You, Y. Li and L. Chen, Sens. Actuators, B, 2015, 211, 507-514.

116 M. Arabi, M. Ghaedi and A. Ostovan, ACS Sustainable Chem. Eng., 2017, 5, 3775-3785.

117 Y. Hu, Y. Li, R. Liu, W. Tan and G. Li, Talanta, 2011, 84, 462-470.

118 N. Kumar, N. Narayanan and S. Gupta, Food Chem., 2018, 255, 81-88.

119 M. Peyrovi, M. Hadjmohammadi and I. Saeidi, Biomed. Chromatogr., 2019, 33, e4404.

120 R. Uzuriaga-Sánchez, A. Wong, S. Khan, M. Pividori, G. Picasso and M. Sotomayor, Mater. Sci. Eng., C, 2017, 74, 365-373.

121 X. Wang, P. Huang, X. Ma, X. Du and X. Lu, J. Chromatogr. A, 2018, 1537, 35-42.

122 S. Xu, J. Li, X. Song, J. Liu, H. Lu and L. Chen, Anal. Methods, 2013, 5, 124-133.

123 R. Gao, Y. Hao, S. Zhao, L. Zhang, X. Cui, D. Liu, Y. Tang and Y. Zheng, RSC Adv., 2014, 4, 56798-56808.

124 R. Gao, Y. Hao, L. Zhang, X. Cui, D. Liu and Y. Tang, Anal. Methods, 2014, 6, 9791-9799.

125 H. Lu and S. Xu, Talanta, 2015, 144, 303-311.

126 B. Wang, H. Deng, M. Wu, S. Xiang, Q. Ma, S. Shi, L. Xie and Y. Guo, Anal. Methods, 2018, 10, 3317-3324.

127 J. Huang, C. Sun, D. Yao, C. Wang, L. Zhang, Y. Zhang, L. Chen and C. Yuan, J. Mater. Chem. B, 2018, 6, 1531-1542.

128 L. Xie, J. Guo, Y. Zhang, Y. Hua, Q. You and S. Shi, Food Chem., 2015, 178, 18-25.

129 S. Miao, M. Wu, H. Zuo, C. Jiang, S. Jin, Y. Lu and H. Yang, J. Agric. Food Chem., 2015, 63, 3634-3645.

130 J. Zhou, Y. Wang, Y. Ma, B. Zhang and Q. Zhang, Appl. Surf. Sci., 2019, 486, 265-273.

131 J. Guo, M. Yu, X. Wei and L. Huang, J. Chem. Eng. Data, 2018, 63, 3068-3073.

132 Z. Lia, C. Lei, N. Wang, X. Jiang, Y. Zeng, Z. Fu, L. Zou, L. He, S. Liu, X. Ao, K. Zhou and S. Chen, J. Chromatogr. B: Anal. Technol. Biomed. Life Sci., 2018, 1100-1101, 113-121.

133 X. He, Z. Lian, L. Tan and J. Wang, J. Chromatogr. A, 2018, 1469, 8-16.
134 X. Yu, H. Liu, J. Diao, Y. Sun and Y. Wang, Sep. Purif. Technol., 2018, 204, 213-219.

135 D. Wang, D. Gao, W. Xu, F. Li, M. Yin, Q. Fu and Z. Xi, Talanta, 2018, 184, 307-315.

136 W. Xu, Q. Dai, Y. Wang, X. Hu, P. Xu, R. Ni and J. Meng, RSC Adv., 2018, 8, 21850-21856.

137 K. Hemmati, R. Sahraei and M. Ghaemy, Polymers, 2016, 101, 257-268.

138 J. Zhou, Y. Wang, J. Bu, B. Zhang and Q. Zhang, ACS Appl. Mater. Interfaces, 2019, 11, 25682-25690.

139 Z. Zhang, H. Wang, H. Wang, C. Wu, M. Li and L. Li, Analyst, 2018, 143, 5849-5856.

140 H. Gholami, M. Arabi, M. Ghaedi, A. Ostovan and A. Bagheri, J. Chromatogr. A, 2019, 1594, 13-22.

141 D. Gao, D. Wang, Q. Fu, L. Wang, K. Zhang, F. Yang and Z. Xia, Talanta, 2018, 178, 299-307.

142 M. Liu, X. Li, J. Li, Z. Wu, F. Wang, L. Liu, X. Tan and F. Lei, J. Colloids Interface Sci., 2017, 504, 124-133.

143 Y. He, Y. Huang, Y. Jin, X. Liu, G. Liu and R. Zhao, ACS Appl. Mater. Interfaces, 2014, 6, 9634-9642.

144 J. Wang and J. Wei, J. Mater. Chem. A, 2017, 5, 4651-4659.

145 Z. Liu, Z. Hu, Y. Liu, M. Meng, L. Ni, X. Meng, G. Zhong, F. Liu and Y. Gao, RSC Adv., 2015, 5, 52369-52381.

146 J. Li, R. Dong, X. Wang, H. Xiong, S. Xu, D. Shen, X. Song and L. Chen, RSC Adv., 2015, 5, 10611-10618.

147 H. Lu and S. Xu, Sens. Actuators B, 2020, 306, 127566.

148 Y. Li, Y. Chen, L. Huang, B. Lou and G. Chen, Analyst, 2017, 142, 302-309.

149 R. Ma, W. Ha, J. Chena and Y. Shi, J. Mater. Chem. B, 2016, 4, 2620-2627.

150 Q. Han, X. Shen, W. Zhu, C. Zhu, X. Zhou and H. Jiang, Biosens. Bioelectron., 2016, 79, 180-186.

151 H. Zhu, H. Yao, K. Xia, J. Liu, X. Yin and W. Zhang, Chem. Eng. J., 2018, 346, 317-328.

152 Q. Liu, K. Zhang, Y. Jin, X. Wang, Y. Liu, H. Liu and M. Xie, Talanta, 2018, 186, 346-353.

153 M. Khajeh, M. Sharifirad, M. Bohlooli and M. GhaffariMoghaddam, RSC Adv., 2016, 6, 54702-54708.

154 Z. Liu, Y. Gao, L. Jin, H. Jin, N. Xu, X. Yu and S. Yu, ACS Sustainable Chem. Eng., 2019, 7, 8168-8175.

155 M. Li, P. Sun, Q. Wu, D. Liu and L. Zhou, Environ. Sci.: Nano, 2018, 5, 2651-2662.

156 Y. He, F. Zhao, C. Zhang, A. EI-Aty, D. Baranenko, A. Hacimüftüoğlu and Y. She, J. Chromatogr. B: Anal. Technol. Biomed. Life Sci., 2019, 1132, 121811.

157 A. Sorribes-Soriano, F. Esteve-Turrillas, S. Armenta, A. Montoya, J. Herrero-Martínez and M. Guardia, J. Chromatogr. A, 2018, 1545, 22-31.

158 D. Ren, J. He and H. Zhang, Anal. Methods, 2014, 6, 3079-3085.

159 I. Mohiuddin, A. Grover, J. Singh, A. Sang-Soo Lee, A. K. Malik and K. Kim, Chem. Eng. J., 2020, 382, 123002.

160 W. Chen, M. Fu, X. Zhu and Q. Liu, Biosens. Bioelectron., 2019, 142, 111492.

161 J. Wang, Z. Meng, M. Xue, L. Qiu, X. Dong, Z. Xu and X. He, New J. Chem., 2017, 41, 1129-1136. 
162 W. J. Tang, T. Zhao, C. H. Zhou, X. J. Guan and H. X. Zhang, Anal. Methods, 2014, 6, 3309-3315.

163 Y. Guo and T. Guo, Chem. Commun., 2013, 49, 1073-1075. 164 H. Fan, J. Wang, Q. Meng and Z. Jin, Food Chem., 2019, 281, 1-7.

165 C. Gong, Y. Wei, L. Liu, A. Zheng, Y. Yang, C. Chow and Q. Tang, Mater. Sci. Eng., C, 2017, 76, 568-578.

166 C. Gong, Y. Yang, Y. Yang, A. Zheng, S. Liu and Q. Tang, J. Colloid Interface Sci., 2016, 481, 236-244.

167 H. Lu and S. Xu, J. Chromatogr. A, 2017, 1051, 10-17.

168 B. Bali and P. Kislay Singh, Sens. Actuators B, 2017, 244, 167-174.

169 D. Fan, H. Li, S. Shi and X. Chen, J. Chromatogr. A, 2016, 1470, 27-32.

170 D. Fan, L. Jia, H. Xiang, M. Peng, H. Li and S. Shi, Food Chem., 2017, 24, 32-36.

171 D. Zang, M. Yan, P. Zhao, L. Ge, S. Liu and J. Yu, Analyst, 2012, 137, 4247-4253.

172 A. Ostovan, M. Ghaedi, M. Arabi and A. Asfaram, J. Chromatogr. A, 2017, 1520, 65-74.

173 J. Zhang, Y. Chen, W. Wu, Z. Wang, Y. Chu and X. Chen, Microchem. J., 2019, 145, 1176-1184.

174 S. Ansari, Anal. Methods, 2017, 9, 3200-3212.

175 P. Wang, A. Zhang, Y. Jin, Q. Zhang, L. Zhang, Y. Peng and S. Du, RSC Adv., 2014, 4, 26063-26073.

176 J. Fan, J. Yu, X. Yang, X. Zhang, T. Yuan and H. Peng, Chem. Eng. J., 2018, 337, 722-732.

177 A. Xie, J. Dai, X. Chen, T. Zou, J. He, Z. Chang, C. Li and Y. Yan, RSC Adv., 2016, 6, 51014-51023.

178 R. Yang, Y. Liu, X. Yan and S. Liu, Talanta, 2016, 161, 114-121.

179 Y. Yang, Y. Sun, H. Chen, X. Dang, Y. Ai, X. Liu and H. Chen, Anal. Methods, 2020, 12, 507-513.

180 S. Xu, L. Chen, J. Li, W. Qin and J. Ma, J. Mater. Chem., 2011, 21, 12047-12053.

181 X. Zheng, T. Xu, R. Shi, N. Lu, J. Zhang, C. Jiang, C. Zhang and J. Zhou, Mater. Lett., 2018, 211, 21-23.

182 Q. Zhao, H. Li, Y. Xu, F. Zhang, J. Zhao, L. Wang, J. Hou, H. Ding, Y. Li, H. Jin and L. Ding, J. Chromatogr. A, 2015, 1376, 26-34.

183 H. Li, L. Zhao, Y. Xu, T. Zhou, H. Liu, N. Huang, J. Ding, Y. Li and L. Ding, Talanta, 2018, 185, 542-549.

184 Z. Wang, T. Qiu, L. Guo, J. Ye, L. He and X. Li, Chem. Eng. J., 2019, 357, 348-357.

185 S. Li, C. Yin, S. Ren, T. Yang, J. Wang and S. Feng, J. Sep. Sci., 2015, 38, 2573-2579.

186 Q. Jia, Y. Ma, Y. Peng, Y. Liu and W. Zhang, Chem. Eng. J., 2018, 342, 293-303.

187 L. Li, K. Yu, M. Tian, Y. Wang, Z. Zhang, G. Jiang and L. Li, Anal. Methods, 2018, 10, 3926-3932.

188 X. Zhao, Y. He, Y. Wang, S. Wang and J. Wang, Food Chem., 2020, 309, 125787.

189 C. Chen, Y. Wang, S. Ding, C. Hong and Z. Wang, Microchem. J., 2019, 147, 191-197.

190 A. Wang, H. Lu and S. Xu, J. Agric. Food Chem., 2016, 64, 5110-5116.
191 W. Huang, X. Hou, Y. Tong and M. Tian, RSC Adv., 2019, 9, 5394-5401.

192 H. Li, X. Hu, Y. Zhang, S. Shi, X. Jiang and X. Chen, J. Chromatogr. A, 2015, 1404, 21-27.

193 Z. Xu, P. Deng, S. Tang, D. Kuang, F. Zhang and J. Li, J. Mater. Chem. B, 2014, 2, 8418-8426.

194 Z. Xu, P. Deng, J. Li, S. Tang and Y. Cui, Mater. Sci. Eng., C, 2019, 94, 684-693.

195 J. Lofgreen, I. Moudrakovski and G. Ozin, ACS Nano., 2011, 5(3), 2277-2287.

196 S. Cen, W. Li, R. He, J. Tan, H. Wang, C. Wei and Y. Tang, RSC Adv., 2017, 7, 37778-37786.

197 S. Xu and H. Lu, Biosens. Bioelectron., 2016, 85, 950-956.

198 Y. Geng, M. Guo, J. Tan, S. Huang, Y. Tang, L. Tan and Y. Liang, Sens. Actuators B, 2019, 281, 821-829.

199 H. Lu, S. Xu and J. Liu, ACS Sens., 2019, 4, 1917-1924.

200 H. Lu, C. Yu and S. Xu, Sens. Actuators B, 2019, 288, 691-698.

201 R. He, Z. Wang, L. Tan, Y. Zhong, W. Li, D. Xing, C. Wei and Y. Tang, Microporous Mesoporous Mater., 2018, 257, 212-221.

202 Y. Chen, D. Li, Z. Bie, X. He and Z. Liu, Anal. Chem., 2016, 88, 1447-1454.

203 X. Pan, X. He and Z. Liu, Anal. Chim. Acta, 2018, 1019, 65-73.

204 Y. Chen, X. Li, D. Yin, D. Li, Z. Bie and Z. Liu, Chem. Commun., 2015, 51, 10929-10932.

205 G. Zhang, L. Jiang, J. Zhou, L. Hu and S. Feng, Chem. Commun., 2019, 55, 9927-9930.

206 Z. Li, P. Guan, X. Hu, S. Ding, Y. Tian, Y. Xu and L. Qian, Polymers, 2018, 10, 298.

207 J. Yang, Y. Li, J. Wang, X. Sun, S. M. Shah, R. Cao and J. Chen, Anal. Chim. Acta, 2015, 853, 311-319.

208 S. Xu, H. Lu, J. Li, X. Song, A. Wang, L. Chen and S. Han, ACS Appl. Mater. Interfaces, 2013, 5, 8146-8154.

209 S. Xu and H. Lu, Biosens. Bioelectron., 2015, 73, 160-166.

210 L. Zhang and L. Chen, ACS Appl. Mater. Interfaces, 2016, 8, 16248-16256.

211 Y. Liu, G. Zhong, Z. Liu, M. Meng, F. Liu and L. Ni, Chem. Eng. J., 2016, 296, 437-446.

212 X. Gu, H. He, C. Wang, Y. Gao, H. Zhang, J. Hong, S. Du, L. Chen and C. Yuan, RSC Adv., 2015, 5, 41377-41384.

213 H. Wang, Y. Liu, S. Yao and P. Zhu, Food Chem., 2018, 240, 1262-1267.

214 F. Yang, D. Hu and X. Dong, Chromatographia, 2015, 78, 45-54.

215 J. Dai, J. He, A. Xie, L. Gao, J. Pan, X. Chen, Z. Zhou, X. Wei and Y. Yan, Chem. Eng. J., 2016, 284, 812-822.

216 Y. Liu, F. Liu, L. Ni, M. Meng, X. Meng, G. Zhong and J. Qiu, RSC Adv., 2016, 6, 54679-54692.

217 X. Pan, X. He and Z. Liu, Anal. Chim. Acta, 2018, 1019, $65-73$.

218 Z. Zhang, J. Li, X. Wang, D. Shen and L. Chen, ACS Appl. Mater. Interfaces, 2015, 7, 9118-9127.

219 Y. Miao, X. Sun, J. Lv and G. Yan, ACS Appl. Mater. Interfaces, 2019, 11, 2264-2272. 
220 M. Jia, Z. Zhang, J. Li, H. Shao, L. Chen and X. Yang, Sens. Actuators B, 2017, 252, 934-943.

221 S. Xu and H. Lu, Chem. Commun., 2015, 51, 3200-3203.

222 W. Gui, H. Wang, Y. Liu and Q. Ma, Sens. Actuators B, 2018, 266, 685-691.

223 M. Li, H. Liu and X. Ren, Biosens. Bioelectron., 2017, 89, 899-905.

224 M. Amjadi and R. Jalili, Biosens. Bioelectron., 2017, 96, 121-126.

225 R. Yang, Y. Liu, X. Yan, S. Liu and H. Zheng, J. Mater. Chem. A, 2016, 4, 9807-9815.

226 H. Lu and S. Xu, J. Chromatogr. A, 2017, 1501, 10-17.

227 W. Chen, M. Xue, F. Xue, X. R. Mu, Z. B. Xu, Z. H. Meng, G. X. Zhu and K. J. Shea, Talanta, 2015, 140, 68-72.
228 Z. Zhang, X. Zhang, D. Niu, Y. Li and J. Shi, J. Hazard. Mater., 2017, 328, 160-169.

229 L. Li, K. Yu, M. Tian, Y. Wang, Z. Zhang, G. Jiang and L. Li, Anal. Methods, 2018, 10, 3926-3932.

230 H. Lu and D. Wei, Analyst, 2019, 144, 6283-6290.

231 Y. Liu, F. Liu, M. Meng, Z. Liu and L. Ni, New J. Chem., 2016, 40, 3821-3832.

232 Z. Feng, Y. Wang, L. Yang and T. Sun, Sci. Total Environ., 2019, 685, 442-450.

233 J. Chen, S. Lei, Y. Xie, M. Wang, J. Yang and X. Ge, ACS Appl. Mater. Interfaces, 2015, 7, 28606-28615.

234 Y. Qin, H. Peng, X. He, W. Li and Y. Zhang, Anal. Chem., 2019, 91, 12696-12703.

235 C. Jia, M. Zhang, Y. Zhang, Z. Ma, N. Xiao, X. He, W. Li and Y. Zhang, ACS Appl. Mater. Interfaces, 2019, 11, 32431-32440. 